\title{
Remote sensing of cloud top pressure/height from SEVIRI: analysis of ten current retrieval algorithms
}

\author{
U. Hamann ${ }^{1,2}$, A. Walther ${ }^{3}$, B. Baum ${ }^{3}$, R. Bennartz ${ }^{3,4}$, L. Bugliaro ${ }^{5}$, M. Derrien ${ }^{6}$, P. N. Francis ${ }^{7}$, A. Heidinger ${ }^{8}$, \\ S. Joro ${ }^{9}$, A. Kniffka ${ }^{10}$, H. Le Gléau ${ }^{6}$, M. Lockhoff ${ }^{10}$, H.-J. Lutz ${ }^{9}$, J. F. Meirink ${ }^{1}$, P. Minnis ${ }^{11}$, R. Palikonda ${ }^{12}$, \\ R. Roebeling ${ }^{9}$, A. Thoss ${ }^{14}$, S. Platnick ${ }^{13}$, P. Watts ${ }^{9}$, and G. Wind ${ }^{13}$ \\ ${ }^{1}$ Royal Netherlands Meteorological Institute (KNMI), De Bilt, the Netherlands \\ ${ }^{2}$ MeteoSwiss, Locarno, Switzerland \\ ${ }^{3}$ University of Wisconsin, Madison, WI, USA \\ ${ }^{4}$ Vanderbilt University, Nashville, TN, USA \\ ${ }^{5}$ Deutsches Zentrum für Luft- und Raumfahrt, Institut für Physik der Atmosphäre, Oberpfaffenhofen, Germany \\ ${ }^{6}$ Météo-France, Lannion, France \\ ${ }^{7}$ Met Office, Exeter, UK \\ ${ }^{8}$ Center for Satellite Applications and Research, NESDIS, NOAA, Madison, WI, USA \\ ${ }^{9}$ EUMETSAT, Darmstadt, Germany \\ ${ }^{10}$ Deutscher Wetterdienst (DWD), Offenbach, Germany \\ ${ }^{11}$ NASA Langley Research Center, Hampton, VA, USA \\ ${ }^{12}$ Science Systems and Applications, Inc., Hampton, VA, USA \\ ${ }^{13}$ NASA Goddard Space Flight Center, Greenbelt, MD, USA \\ ${ }^{14}$ Swedish Meteorological and Hydrological Institute (SMHI), Norrköping, Sweden
}

Correspondence to: U. Hamann (ulrich.hamann@meteoswiss.ch)

Received: 14 November 2013 - Published in Atmos. Meas. Tech. Discuss.: 20 January 2014

Revised: 11 July 2014 - Accepted: 14 July 2014 - Published: 9 September 2014

\begin{abstract}
The role of clouds remains the largest uncertainty in climate projections. They influence solar and thermal radiative transfer and the earth's water cycle. Therefore, there is an urgent need for accurate cloud observations to validate climate models and to monitor climate change. Passive satellite imagers measuring radiation at visible to thermal infrared (IR) wavelengths provide a wealth of information on cloud properties. Among others, the cloud top height (CTH) - a crucial parameter to estimate the thermal cloud radiative forcing - can be retrieved. In this paper we investigate the skill of ten current retrieval algorithms to estimate the CTH using observations from the Spinning Enhanced Visible and InfraRed Imager (SEVIRI) onboard Meteosat Second Generation (MSG). In the first part we compare ten SEVIRI cloud top pressure (CTP) data sets with each other. The SEVIRI algorithms catch the latitudinal variation of the CTP in a similar way. The agreement is better in the extratropics than in the tropics. In the tropics multi-layer clouds and thin cirrus
\end{abstract}

layers complicate the CTP retrieval, whereas a good agreement among the algorithms is found for trade wind cumulus, marine stratocumulus and the optically thick cores of the deep convective system.

In the second part of the paper the SEVIRI retrievals are compared to CTH observations from the Cloud-Aerosol LIdar with Orthogonal Polarization (CALIOP) and Cloud Profiling Radar (CPR) instruments. It is important to note that the different measurement techniques cause differences in the retrieved CTH data. SEVIRI measures a radiatively effective $\mathrm{CTH}$, while the $\mathrm{CTH}$ of the active instruments is derived from the return time of the emitted radar or lidar signal. Therefore, some systematic differences are expected. On average the CTHs detected by the SEVIRI algorithms are 1.0 to $2.5 \mathrm{~km}$ lower than CALIOP observations, and the correlation coefficients between the SEVIRI and the CALIOP data sets range between 0.77 and 0.90 . The average $\mathrm{CTHs}$ derived by the SEVIRI algorithms are closer to the CPR measurements 
than to CALIOP measurements. The biases between SEVIRI and CPR retrievals range from $-0.8 \mathrm{~km}$ to $0.6 \mathrm{~km}$. The correlation coefficients of CPR and SEVIRI observations vary between 0.82 and 0.89 . To discuss the origin of the CTH deviation, we investigate three cloud categories: optically thin and thick single layer as well as multi-layer clouds. For optically thick clouds the correlation coefficients between the SEVIRI and the reference data sets are usually above 0.95 . For optically thin single layer clouds the correlation coefficients are still above 0.92 . For this cloud category the SEVIRI algorithms yield CTHs that are lower than CALIOP and similar to CPR observations. Most challenging are the multi-layer clouds, where the correlation coefficients are for most algorithms between 0.6 and 0.8. Finally, we evaluate the performance of the SEVIRI retrievals for boundary layer clouds. While the CTH retrieval for this cloud type is relatively accurate, there are still considerable differences between the algorithms. These are related to the uncertainties and limited vertical resolution of the assumed temperature profiles in combination with the presence of temperature inversions, which lead to ambiguities in the CTH retrieval. Alternative approaches for the $\mathrm{CTH}$ retrieval of low clouds are discussed.

\section{Introduction}

About $70 \%$ of the earth's surface is covered with clouds. They play an essential role in weather and climate interacting strongly with solar and terrestrial radiation (Cess et al., 1989). In the solar wavelength region, clouds cool the earth by reflecting sunlight back to space. At the same time clouds tend to warm the earth by absorbing and re-emitting thermal radiation emitted by the surface and lower atmosphere (Wielicki et al., 1995). While solar radiative transfer is mainly influenced by the cloud cover and the optical depth of the clouds, the thermal effect is also determined by their cloud top temperature. Thus, optically thick, low level clouds usually have a negative net radiative forcing as their thermal effect is small and reflection of solar radiance dominates. In contrast, the net radiative effect of high level clouds is often positive (in particular during night and for optically thin cirrus over warm surfaces during day) because the thermal contrast between them and the surface is large (Liou, 1986; Boucher, 1999; Meyer et al., 2002; Schumann et al., 2012).

Hence, detailed monitoring of cloud properties - such as cloud fraction, cloud top temperature, cloud particle size and cloud water path - is needed to understand the role of clouds in the weather and climate system. Cloud remote sensing from space is an important and effective tool to monitor climate change and to evaluate weather and climate models. Satellites are able to observe cloud properties globally, and, in particular, passive imagers provide observations of large areas with a high temporal resolution enabling investigations of the evolutions and life times of cloud systems.
The International Satellite Cloud Climatology Project (ISCCP) has monitored cloud properties including cloud top temperature and pressure as well as cloud water path and cloud optical depth since 1983 from geostationary satellites and the Advanced Very High Resolution Radiometer (AVHRR) on the polar orbiting NOAA and MetOp satellites (Rossow and Schiffer, 1999). But little information about cloud phase, particle size and night time cloud heights is provided as only two satellite channels are used for temporal consistency. Many other techniques have been developed since the start of ISCCP to derive those additional parameters utilizing multiple channels now available on most modern geostationary and sun-synchronous satellite imagers. In particular, the use of more channels in the visible to long-wave infrared (IR) wavelength region $(400 \mathrm{~nm}-15 \mu \mathrm{m})$ is very beneficial.

Despite the progress in this area, the interpretation of the measured radiance remains challenging for the following reasons: first, observations do not fully constrain the retrieval problem. Most information originates from the cloud top, but clouds are vertically extended and have a complex structure. Second, satellite pixels typically cover an area of a few $\mathrm{km}^{2}$. The clouds within this area are inhomogeneous. Radiation from neighboring areas as well as the three-dimensional structure of clouds influence the observed radiance, which is normally neglected in cloud remote-sensing algorithms (e.g., Zinner and Mayer, 2006). Hence, the common assumption of a plane parallel single cloud layer can only approximate reality. Third, the thermal emission of the cloud comes from within the uppermost cloud layer. Therefore, the retrieved cloud top height $(\mathrm{CTH})$ is a radiatively effective one and not the physical cloud boundary. Fourth, in case of temperature inversions, the conversion from observed brightness temperature to CTH can be ambiguous and may lead to large displacements. Furthermore, during the day retrievals are challenging for certain observation geometries such as the sun glint angular envelope and high solar zenith angles. Finally, a number of facts are only partially known: the shapes of ice crystals that determine their scattering and absorption properties, the state of the atmosphere, the albedo and emissivity of the surface, calibration and degradation of the satellite sensor and uncertainties in the spectral response function. This limited knowledge exacerbates cloud remote sensing in practice even more, especially for optically thin clouds. The radiative effect of these uncertainties can be significant compared to the cloud effect itself and, therefore, retrieved cloud properties may also be uncertain.

Many research groups have developed cloud retrievals tackling all the above issues. Comparisons and validations of these retrievals are needed to understand the differences and improve our understanding. Recently, average cloud properties from twelve global Level 3 data sets were compared on climatological scales in the framework of the GEWEX cloud assessment (Stubenrauch et al., 2013). The comparison included multi-spectral imagers, multi-angle multi-spectral 
imagers, IR sounders and active instruments. Stubenrauch et al. (2013) stated that CTH measurements are comparable considering the different sensor sensitivities. In particular, they pointed out that passive imagers measure a radiatively effective CTH. Furthermore, the GEWEX cloud assessment investigated the regional and vertical distributions as well as diurnal and seasonal cycles.

As averaged cloud properties are used in the GEWEX cloud assessment, differences of the Level 2 to Level 3 aggregation procedure as well as differences among the retrieval methods themselves are identified as cause for the observed deviations. Therefore, an additional in-depth analysis of Level 2 cloud products reveal even more insight into the characteristics of retrieval algorithms. This is why the Cloud Retrieval Evaluation Workshop (CREW) project was founded (Roebeling et al., 2012). Exchanges during the CREWs in 2006, 2009 and 2011 triggered the creation of a cloud retrieval database. A large number of research groups provided their retrieval results to this database, thus enabling a systematic evaluation similar to the GEWEX cloud assessment, but for Level 2 products. This is the first effort of its kind since the pre-ISCCP algorithm inter-comparisons (Rossow et al., 1985).

The current paper presents the inter-comparison and validation results of ten CTH retrieval algorithms using observations of the Spinning Enhanced Visible and InfraRed Imager (SEVIRI) onboard the geostationary Meteosat Second Generation (MSG) platform using the CREW database. The paper is structured as follows: in Sect. 2 we give a description of the satellite sensors used, review the fundamentals of cloud top height/pressure retrieval methods and give an overview of the Cloud Retrieval Evaluation Workshop database. In Sects. 3 and 4 we present the results of the SEVIRI retrieval inter-comparison and the comparison with Cloud-Aerosol LIdar with Orthogonal Polarization (CALIOP) and CPR. In Sect. 5 we discuss and summarize our findings.

\section{Data sets and methods}

Section 2.1 summarizes the characteristics of the satellite sensors used in this study. In Sect. 2.2 we introduce common retrieval methods for clouds from passive sensors in general, followed by a description of the CREW cloud retrieval database in Sect. 2.3.

\subsection{Instrumentation}

In this paper we inter-compare retrievals using observations from the SEVIRI instrument (Schmetz et al., 2002) on the geostationary Meteosat- 9 satellite located at the orbital position $0^{\circ} \mathrm{E}$ and $0^{\circ} \mathrm{N}$. Observations are possible up to a viewing zenith angle of ca. $70^{\circ}$ thus including mainly Africa, Europe, the Atlantic Ocean as well as small parts of South America and the Indian Ocean. SEVIRI has eleven spectral bands with $3 \mathrm{~km}$ spatial resolution at the sub-satellite point: three solar channels at $0.6,0.8$ and $1.6 \mu \mathrm{m}$, one combined solar/thermal channel at $3.9 \mu \mathrm{m}$, two water vapor channels at 6.2 and $7.3 \mu \mathrm{m}$, one ozone channel at $9.6 \mu \mathrm{m}$, one $\mathrm{CO}_{2}$ channel at $13.4 \mu \mathrm{m}$ and three IR window channels at 8.7, 10.8 and $12.0 \mu \mathrm{m}$. The seven thermal channels are calibrated onboard, while the solar channels are not and require vicarious calibration (Govaerts et al., 2001). Furthermore, SEVIRI has one high-resolution broadband visible (HRV) channel at $1 \mathrm{~km}$ spatial resolution. The SEVIRI sensor scans the observation disk every $15 \mathrm{~min}$. The scan starts in the south and takes $12 \mathrm{~min}$ to reach the northernmost point. The high temporal resolution enables the study of the evolution of cloud systems including the diurnal cycle.

In the second part of the paper, we compare the $\mathrm{CTH}$ retrievals from SEVIRI with measurements from active instruments, namely the Cloud-Aerosol LIdar with Orthogonal Polarization (CALIOP) and the Cloud Profiling Radar (CPR). CALIOP is the main instrument on the CALIPSO satellite launched in April 2006 (Winker et al., 2003, 2007, 2010; Liu et al., 2005; Hostetler et al., 2006); it is a dual wavelength lidar (532 and $1064 \mathrm{~nm}$ ). The primary products are profiles of total backscatter, from which further products like cloud and aerosol properties are derived (Vaughan et al., 2005). The instrument also measures the linear depolarization of the backscattered return signal at $532 \mathrm{~nm}$ allowing for the discrimination of cloud phase and the identification of non-spherical aerosols. On the earth's surface individual CALIOP beams have a width of about $70 \mathrm{~m}$ with a sampling distance of $333 \mathrm{~m}$. The vertical resolution of the CALIOP products is 30 to $60 \mathrm{~m}$. The lidar retrieval is based on the lidar equation (Hostetler et al., 2006):

$E_{\mathrm{r}}(\lambda, r)=E_{\mathrm{t}} \frac{\mathrm{d} r A_{0}}{r^{2}} k(\lambda) \beta(r) T^{2}(r)$,

where $E_{\mathrm{r}}$ and $E_{\mathrm{t}}$ are the received and transmitted energy, $r$ is the range from the lidar, $\mathrm{d} r$ the range resolution, $\lambda$ the wavelength of the transmitted pulse and $\beta(r)$ the atmospheric backscatter coefficient. $A_{0} / r^{2}$ is the acceptance solid angle of the receiving optics with $A_{0}$ being the collecting area of the telescope. The instrument constant $k(\lambda)$ considers the response of the receiver like the spectral transmission. The signal is attenuated according to the two-way transmission $T^{2}(r)$. The transmission through the atmosphere is set by the molecular scattering in the Rayleigh regime as well as scattering with cloud and aerosol particles. Therefore, CALIOP is very sensitive to small particles and able to detect cloud ice water content as low as $0.1 \mathrm{mg} \mathrm{m}^{-3}$ (Avery et al., 2012). CALIOP provides the unambiguous $\mathrm{CTH}$ of the uppermost cloud layer in almost all situations. In case of multi-layer clouds, CALIOP provides information for layers down to a level where the lidar signal is fully attenuated. This occurs where the cumulative optical depth is $3-5$. Interpretation of CALIOP measurements suffers from a low signal-tonoise ratio. Therefore, measurements are usually averaged 
over several lidar shots. In this way, sub-visible clouds with a very small optical depth down to 0.01 can be detected. Its high sensitivity and vertical resolution make CALIOP an excellent system for the validation of CTH retrievals from passive radiometers.

The CPR onboard CloudSat launched in April 2006 is a $94 \mathrm{GHz}$ nadir-looking radar. It measures the backscattered signal as a function of distance from the radar (Stephens et al., 2002, 2008; Tanelli et al., 2008). As clouds are weak scatterers in the microwave region, the CPR is designed for maximal sensitivity. Its dynamic range is $70 \mathrm{~dB}$ and its calibration accuracy is $1.5 \mathrm{~dB}$. The attenuation of the radar signal is influenced by absorbing gases (primarily water vapor), water and ice clouds as well as precipitating particles. With a pulse length of $3.3 \mu \mathrm{s}$, CPR provides cloud and precipitation information with $500 \mathrm{~m}$ vertical resolution between the surface and $30 \mathrm{~km}$. The radar measurements along track are averaged over $0.32 \mathrm{~s}$ time intervals, producing a horizontal resolution of $1.4 \mathrm{~km}$ (cross-track) by $1.7 \mathrm{~km}$ (along-track). The radar signal is interpreted with the radar equation

$E_{\mathrm{r}}(\lambda, r)=E_{\mathrm{t}} \frac{1}{(4 \pi)^{3} r^{2} L_{\mathrm{a}}} \lambda^{2} \sigma G_{\mathrm{r}} G^{2} \Omega \Delta$,

where $E_{\mathrm{r}}$ is the output energy of the receiver, $E_{\mathrm{t}}$ the transmitted energy, $\lambda$ the wavelength, $\sigma$ the range resolved radar cross section per unit volume, $G_{\mathrm{r}}$ the receiver gain, $G$ the antenna gain, $r$ the range to the atmospheric target, $\Omega$ the integral of the normalized two-way antenna pattern, $\Delta$ the integral of the received waveform shape and $L_{\mathrm{a}}$ the two-way atmospheric loss. As meteorological radars work in the Rayleigh regime, the extinction efficiency is less compared to the Mie regime; hence, radar can penetrate further into the cloud. The radar cross section can be written as

$\sigma=\frac{\pi^{5}}{\lambda^{4}}|K|^{2} \sum_{i} D_{i}^{6}$

where $D_{i}$ is the diameter of the scattering particles. $|K|^{2}$ is defined as

$|K|^{2}=\left|\frac{\varepsilon_{d}-1}{\varepsilon_{d}+2}\right|^{2}$

where $\varepsilon_{d}$ is the dielectric constant. For CPR $|K|^{2}=0.683$ for water and $|K|^{2}=0.176$ for ice (Ray, 1972). Consequently, the reflectivity of water particles is around $0.683 / 0.176=$ 3.88 or $5.89 \mathrm{dBz}$ higher for water particles than for ice particles of the same size and shape. As the volumetric radar cross section $\eta$ is proportional to $D_{i}^{6}$, the radar is much more sensitive to larger particles than to smaller ones.

\subsection{Cloud top height retrieval methods}

With observations of the radiance and a priori information of the atmospheric state, in particular the temperature profile and concentration of absorbing gases, the radiatively effective CTH can be retrieved representing the top height of a plane parallel, homogeneous cloud that cause the same radiance $I_{v}$ at the top of the atmosphere as observed. In general, the measured radiance $I_{v}$ at wave number $v$ depends on the cloud top pressure $p_{\mathrm{c}}$ as follows (Liou, 2002):

$I_{v}=\left(1-\eta \varepsilon_{v}\right)\left(I_{\mathrm{s}}+I_{\mathrm{b}}\right) t_{v}\left(p_{\mathrm{c}}, 0\right)+I_{\mathrm{c}}+I_{\mathrm{a}}$,

where the contribution from the surface is described by

$I_{\mathrm{s}}=B_{v}\left(T_{\mathrm{s}}\right) t_{v}\left(p_{\mathrm{s}}, p_{\mathrm{c}}\right)$

the contribution of the atmosphere below the cloud by

$I_{\mathrm{b}}=\int_{p_{\mathrm{s}}}^{p_{\mathrm{c}}} B_{v}(T(p)) \frac{\partial t_{v}\left(p, p_{\mathrm{c}}\right)}{\partial p} \mathrm{~d} p$,

the contribution of the cloud itself by

$I_{\mathrm{c}}=\eta \varepsilon_{v} B_{v}\left(T_{\mathrm{c}}\right) t_{v}\left(p_{\mathrm{c}}, 0\right)$,

and the contribution of the atmosphere above the cloud by

$I_{\mathrm{a}}=\int_{p_{\mathrm{c}}}^{0} B_{v}(T(p)) \frac{\partial t_{v}(p, 0)}{\partial p} \mathrm{~d} p$.

In these equations $\eta$ is the cloud fraction, $\varepsilon_{v}$ the spectral emissivity of the cloud, $B_{v}$ the Planck radiation, $t_{v}\left(p_{1}, p_{2}\right)$ the transmissivity between pressures $p_{1}$ and $p_{2}$ and $p_{\mathrm{c}}, p_{\mathrm{s}}$, $T_{\mathrm{c}}$ and $T_{\mathrm{S}}$ are pressure and temperature of the cloud and the surface, respectively.

\subsubsection{Radiance fitting}

One basic method to derive the cloud top pressure (CTP) assumes a fully covered field of view $\eta=1$ and optically thick clouds $\varepsilon_{v}=1$. The term $1-\eta \varepsilon_{v}$ on the right hand side in Eq. (5) vanishes, being tantamount to no contribution from the surface and the atmosphere below the cloud. Assuming an atmospheric temperature and humidity profile, the radiance can be calculated using a radiative transfer model. The CTP is found by minimizing the difference between the simulated and observed radiance. With this method and under the above-mentioned assumptions, the CTP can be derived by using only a single channel. It is favorable to use a wavelength with a large atmospheric transmissivity to minimize the influence of the atmosphere above the cloud on the retrieval. For SEVIRI, the $10.8 \mu \mathrm{m}$ channel is commonly chosen. It is possible to extend this retrieval method taking cloud cover $\eta$ and/or the spectral cloud emissivity $\varepsilon_{v}$ explicitly into account (Chahine, 1974; Wielicki and Coakley Jr, 1981; Roebeling et al., 2006; Roebeling, 2008). The cloud cover $\eta$ can be estimated using the high-resolution channel of SEVIRI. Furthermore, the spectral emissivity $\varepsilon_{v}$ can be estimated from the approximate $2: 1$ relationship between the 
cloud optical depths at visible and IR window-channel wavelengths. Rossow and Schiffer (1999) solve first for the visible optical depth $\tau_{\text {vis }}$ using the reflected radiance. Then, the emissivity $\varepsilon_{v}$ is computed as

$\varepsilon_{v}=1-\exp \left(-0.5 \tau_{\text {vis }} / \mu\right)$

where $\mu$ is cosine of the viewing zenith angle. Taking the semi-transparency and coverage of the cloud layer into account, the retrieval results of the radiance fitting method can be significantly improved.

In the following we call this retrieval method radiance fitting. It is known that this method tends to overestimate CTP for partial cloud cover and semi-transparent clouds, if these effects are not taken into account (e.g., Holz et al., 2006).

\subsubsection{Optimal estimation}

A generalization of the radiance fitting is the optimal estimation (OE) method. It uses several channels and any available prior information with suitable weighting according to errors. Essential diagnostic outputs of the OE method are a measure of the model fit to the observation, that is, the cost function $J$, and formal error estimates of the retrieved parameters. The cost function $J$ is defined as follows (Rodgers, 2000):

$$
\begin{aligned}
J(\boldsymbol{x})= & \left(\boldsymbol{y}(\boldsymbol{x})-\boldsymbol{y}_{\mathrm{m}}\right)^{\mathrm{T}} \mathbf{S}_{y}^{-1}\left(\boldsymbol{y}(\boldsymbol{x})-\boldsymbol{y}_{\mathrm{m}}\right) \\
& +\left(\boldsymbol{x}-\boldsymbol{x}_{\mathrm{a}}\right)^{\mathrm{T}} \mathbf{S}_{\mathrm{a}}^{-1}\left(\boldsymbol{x}-\boldsymbol{x}_{\mathrm{a}}\right)
\end{aligned}
$$

where $\boldsymbol{y}_{\mathrm{m}}$ are the measurements and $\boldsymbol{y}(\boldsymbol{x})$ are the radiances simulated by assuming the state $\boldsymbol{x} . \boldsymbol{x}_{\mathrm{a}}$ is an estimate of the state prior to the retrieval and $\mathbf{S}_{y}^{-1}$ and $\mathbf{S}_{\mathrm{a}}^{-1}$ are the inverted error covariance matrices of the measurements and the prior state, respectively. The state vector $\boldsymbol{x}$ is varied to minimize the cost function $J$ yielding the optimal state given the observation $\boldsymbol{y}_{\mathrm{m}}$, the prior knowledge, and their respective uncertainties. In the context of this paper, the state parameter $\boldsymbol{x}$ contains the physical properties of the cloud. Using a window channel alone leads to very large solution spaces for CTP retrievals for cirrus, while the inclusion of a single absorbing channel greatly decreases the solution space (Heidinger et al., 2010). This is an approach commonly adopted for use with SEVIRI as well as other polar-orbiting imagers. Iterative techniques can also be used to simultaneously fit more than one parameter to the same number of channels. Among others, OE has been applied to AVHRR (Walther and Heidinger, 2012), AlongTrack Scanning Radiometer (ATSR) (Poulsen et al., 2011), SEVIRI (Watts et al., 2011), a combined Medium Resolution Imaging Spectrometer (MERIS) and Advanced AlongTrack Scanning Radiometer (AATSR) data set (Lindstrot et al., 2010) and Michelson Interferometer for Passive Atmospheric Sounding (MIPAS) (Hurley et al., 2011).

\subsubsection{Radiance ratioing}

Another approach to retrieve $\mathrm{CTP}$ is the radiance ratioing method (also sometimes named split window or $\mathrm{CO}_{2}$ slicing) (Chahine, 1974; Cavia and Tomassini, 1978; Smith and Platt, 1978; Menzel et al., 1983, 2008; Wylie and Menzel, 1989; Zhang and Menzel, 2002). Subtracting the clear sky radiance $I_{v}^{\text {clr }}$ from the all sky observation $I_{v}$ in Eq. (5) and integration by parts leads to

$I_{v}-I_{v}^{\mathrm{clr}}=\eta \varepsilon_{v} \int_{p_{\mathrm{s}}}^{p_{\mathrm{c}}} t_{v}(p, 0) \frac{\partial B_{v}(T(p))}{\partial p} \mathrm{~d} p$,

see, e.g., Liou (2002). The clear sky radiance can be simulated with a radiative transfer model or estimated by locating clear sky measurements in the vicinity of the observation (Smith and Frey, 1990). For radiance ratioing, Eq. (12) for a wave number $v_{1}$ is divided by the same equation for a second wave number $v_{2}$; hence, the formulation becomes independent of the cloud fraction $\eta$. Channel combinations for radiance ratioing are preferably chosen in that way that the gaseous absorptions for $v_{1}$ and $v_{2}$ are different, but the spectral cloud emissivities $\varepsilon_{v}$ are similar. For hyperspectral sounders, e.g., Atmospheric InfraRed Sounder (AIRS), commonly used channel combinations are located around $15 \mu \mathrm{m}$ using the absorption feature of $\mathrm{CO}_{2}$; hence, this technique is called $\mathrm{CO}_{2}$ slicing. The retrieval uncertainty depends on the atmospheric temperature and trace gas profiles (Holz et al., 2006; Smith and Frey, 1990) and, if not taken explicitly into account, on the spectral change of the cloud emissivity. Accurate calculation of the latter is shown to improves the CTP retrieval accuracy (Zhang and Menzel, 2002). For the SEVIRI instrument, the $10.8 \mu \mathrm{m}$ channel is commonly used in combination with the 12.0 or $13.4 \mu \mathrm{m}$ channel. The wavelengths of the satellite channels are further apart from each other for SEVIRI than for IR sounders, so that a calculation of the cloud emissivities is necessary. Parameterizations of cloud long-wave radiative properties are used for this purpose (e.g., Hu and Stamnes, 1993; Baum et al., 2005a, b, 2007).

\subsection{The CREW database}

In the framework of the Cloud Retrieval Evaluation Workshop (CREW), a common cloud retrieval database was built to investigate strengths and weaknesses of currently available cloud property retrieval algorithms using passive imager observations. The cloud properties stored in the CREW database are listed in Table 1.

In this paper the main focus is on the SEVIRI data sets, but also polar orbiting sensors such as the MODerate resolution Imaging Spectroradiometer (MODIS) onboard the EOS-Terra and Aqua satellites and the AVHRR as well as the Multi-angle Imaging SpectroRadiometer (MISR), the POLarization and Directionality of the Earth's Reflectances 
Table 1. Cloud properties in the CREW database.

\begin{tabular}{ll}
\hline Acronym & Cloud parameter \\
\hline CMK & Cloud mask \\
CPH & Cloud phase \\
CTT & Cloud top temperature \\
CTP & Cloud top pressure \\
CTH & Cloud top height \\
COD & Cloud optical depth \\
REF & Effective radius \\
LWP & Liquid water path \\
IWP & Ice water path \\
\hline
\end{tabular}

Table 2. Days and core hours of the CREW database.

\begin{tabular}{lcc}
\hline Date & Core hours & A-train orbit numbers \\
\hline 13 Jun 2008 & $12: 00-15: 30$ & $11317,11318,11319$ \\
17 Jun 2008 & $22: 15-24: 00$ & 11381,11382 \\
18 Jun 2008 & $00: 00-01: 45$ & 11383 \\
22 Jun 2008 & $10: 30-12: 15$ & 11447,11448 \\
3 Jul 2008 & $10: 00-12: 00$ & $11607,11608,11609$ \\
\hline
\end{tabular}

(POLDER) and the AIRS retrievals are included in the database. The database is complemented with cloud measurements that serve as a reference, including the Advanced Microwave Scanning Radiometer for EOS (AMSR-E) observations and the active instruments CPR on CloudSat and CALIOP on CALIPSO.

The CREW database contains five days of data, see Table 2. During these days the NOAA-18 satellite was aligned with the A-train orbit for several hours. In this paper we focus on 13 June 2008, as the data set is most complete for this day.

In total, twelve institutions from Europe and USA participate in the CREW inter-comparison and validation of their SEVIRI data sets. This paper investigates the ten data sets providing cloud top height or cloud top pressure retrievals. The acronyms and contact persons of the participating institutions are listed in Table 3.

As a first step the raw signal measured by SEVIRI is converted into a radiance. Most of the algorithms use the L1 radiance product as provided by EUMETSAT. Only a few algorithms use an alternative calibration. The CMS algorithm uses the calibration described by Meirink et al. (2013). The LAR algorithm uses an additional calibration for the $0.65 \mu \mathrm{m}$ channel against the Aqua MODIS channel and a calibration for the $3.9 \mu \mathrm{m}$ channel against GOES measurements (Minnis et al., 2002a, b). The UKM algorithm uses an ad hoc calibration for the $13.4 \mu \mathrm{m}$ channel. Recent research in the framework of the Global Space-based Inter-Calibration System (GSICS) demonstrated that the $13.4 \mu \mathrm{m}$ is probably biased by contamination with ice (Hewison and Müller, 2013). GSICS provides time-dependent calibration coefficients for
Table 3. Participating institutions.

\begin{tabular}{lll}
\hline Acronym & Institute & Contact person \\
\hline AWG & NOAA - CIMSS & A. Heidinger, A. Walther \\
CMS & CM SAF & A. Kniffka, M. Lockhoff \\
DLR & DLR & L. Bugliaro \\
EUM & EUMETSAT & H.-J. Lutz \\
GSF & NASA Goddard & S. Platnick, G. Wind \\
LAR & NASA Langley & P. Minnis, R. Palikonda \\
MFR & Météo-France & H. Le Gléau, M. Derrien \\
MPF & EUMETSAT & S. Joro \\
OCA & EUMETSAT & P. Watts \\
UKM & UK Met Office & P. Francis \\
\hline
\end{tabular}

the SEVIRI IR channels according to an inter-calibration against Metop-A IASI. The GSICS methodology of postcalibration is very advanced. At the moment none of the SEVIRI algorithms uses the GSICS calibration coefficients. To estimate the benefit of the GSICS calibration on the CTH retrieval, a small case study is performed with the CMS algorithm for the 13 June 2008, 12:00 UTC. The effects on the retrieval results are small in comparison to the fundamental observation differences of the different sensors and the deviations among the SEVIRI algorithms discussed later in this paper. Nevertheless, the GISCS calibration changes the CTH retrieval results for some individual cases by up to $12 \mathrm{~km}$. As GSICS provides the most sophisticated calibration, taking advantage of it will certainly be beneficial for every algorithm.

After the calibration of the radiance, the CTP/CTH is derived. All variants of CTP retrieval methods discussed in Sect. 2.2 are applied in one or more algorithms. An overview of the retrieval methods and satellite channels used by the SEVIRI retrieval algorithms is given in Table 4. Many algorithms apply a combination of several methods. For optically thick and low clouds, many groups use radiance fitting with the IR window channel at $10.8 \mu \mathrm{m}$. For semi-transparent or broken clouds it is necessary to employ the radiance ratioing method. But the algorithms use different criteria for the identification of cloud regimes for which radiance ratioing is applied.

The Algorithm Working Group (AWG) algorithm exploits the $10.8,12.0$ and $13.4 \mu \mathrm{m}$ channels on SEVIRI and MODIS. The mathematics are described in Heidinger and Pavolonis (2009), and the motivation for this set of channels is given in Heidinger et al. (2010). The AWG applies an analytical forward model couched in an optimal estimation framework. The retrieved parameters are the cloud top temperature (CTT), $10.8 \mu \mathrm{m}$ cloud emissivity and an IR microphysical index (beta). From these parameters the CTP is derived. Effective radius (REF) and cloud optical depth (COD) are retrieved in a separate step. If the AWG cloud typing detects multi-layered clouds, an opaque lower cloud is inserted at a height of an unobscured low cloud in the vicinity. 
Table 4. SEVIRI cloud top height retrieval methods.

\begin{tabular}{|c|c|c|c|c|}
\hline Acro. & Method & Channels $(\mu \mathrm{m})$ & Aux. data & Citations \\
\hline AWG & optimal estimation & $10.8,12.0,13.4$ & NCEP & $\begin{array}{l}\text { Menzel et al. (2008); Heidinger and Pavolonis (2009); } \\
\text { Heidinger et al. (2010); Baum et al. (2012) }\end{array}$ \\
\hline CMS & $\begin{array}{l}\text { (1) radiance fitting } \\
\text { (2) intersection method } \\
\text { (3) radiance ratioing }\end{array}$ & $\begin{array}{c}10.8 \\
6.2,7.3,10.8,13.4 \\
6.2,7.3,10.8,13.4\end{array}$ & ERA interim & $\begin{array}{l}\text { Derrien and Le Gléau (2005, 2010, 2013); } \\
\text { Schmetz et al. (1993); Appendix C; } \\
\text { Menzel et al. (1983) }\end{array}$ \\
\hline DLR & $\begin{array}{l}\text { (1) radiance fitting } \\
\text { (2) radiance ratioing }\end{array}$ & $\begin{array}{c}10.8 \\
10.8,13.4\end{array}$ & ECMWF & $\begin{array}{l}\text { Meerkötter and Bugliaro (2009); Bugliaro et al. (2011); } \\
\text { Ewald et al. (2013) }\end{array}$ \\
\hline EUM & $\begin{array}{l}\text { (1) radiance fitting } \\
\text { (2) radiance ratioing }\end{array}$ & $\begin{array}{c}10.8 \\
6.2,7.3,10.8,12.0,13.4\end{array}$ & ECMWF & Lutz et al. (2011) \\
\hline GSF & $\begin{array}{l}\text { (1) optimal estimation } \\
\text { (2) radiance fitting }\end{array}$ & $\begin{array}{c}3.9,8.7,10.8,12.0,13.4 \\
10.8\end{array}$ & ECMWF & $\begin{array}{l}\text { Platnick et al. (2003); King et al. (2006); } \\
\text { Seemann et al. (2008); Heidinger and Pavolonis (2009); } \\
\text { Wind et al. (2010) }\end{array}$ \\
\hline LAR & $\begin{array}{l}\text { (1) optimal estimation } \\
\text { (2) radiance ratioing }\end{array}$ & $\begin{array}{l}0.6,3.9,10.8,12.0 \\
10.8,13.4\end{array}$ & NOAA GFS & Minnis et al. (2008b, 2010, 2011); Chang et al. (2010) \\
\hline MFR & $\begin{array}{l}\text { (1) radiance fitting } \\
\text { (2) intersection method } \\
\text { (3) radiance ratioing }\end{array}$ & $\begin{array}{c}10.8 \\
6.2,7.3,10.8,13.4 \\
6.2,7.3,10.8,13.4\end{array}$ & ECMWF & $\begin{array}{l}\text { Derrien and Le Gléau (2005, 2010, 2013); } \\
\text { Schmetz et al. (1993); Appendix C; } \\
\text { Menzel et al. (1983) }\end{array}$ \\
\hline MPF & $\begin{array}{l}\text { (1) radiance fitting } \\
\text { (2) radiance ratioing }\end{array}$ & $\begin{array}{c}10.8 \\
6.2,7.3,10.8,12.0,13.4\end{array}$ & ECMWF & Lutz et al. (2011) \\
\hline OCA & optimal estimation & all, but $3.9,9.6$ & ECMWF & Watts et al. (2011) \\
\hline UKM & $\begin{array}{l}\text { (1) radiance ratioing } \\
\text { (2) radiance fitting }\end{array}$ & $\begin{array}{c}10.8,12.0,13.4 \\
10.8\end{array}$ & MetOffice & $\begin{array}{l}\text { Eyre and Menzel (1989); Moseley (2003); } \\
\text { Saunders et al. (2006); Francis et al. (2008) }\end{array}$ \\
\hline
\end{tabular}

The CMS and MFR share the same algorithm heritage and are similar. The cloud type product of the NWC SAF is employed to separate opaque clouds from semi-transparent and broken clouds. For very low, low or medium thick clouds, radiance fitting is applied to derive CTH. For high thick clouds either the radiance ratioing or the radiance fitting is used. And for high semi-transparent clouds, either the radiance ratioing or an intersection method (Schmetz et al., 1993) is used. Here, the intersection method exploits the $10.8 \mu \mathrm{m}$ channel in combination with one of the sounding channels $6.2,7.3$ or $13.4 \mu \mathrm{m}$. The minimum CTP result of these channel combinations is chosen as the final result. The most distinct difference between the CMS and MFR algorithm is the retrieval of the CTHs of boundary layer clouds, see Sect. 4.2.4.

EUM and MPF are both developed by EUMETSAT and share the same algorithm heritage. MPF (MSG Meteorological Products Extraction Facility Algorithm) is the operational algorithm of EUMETSAT, while EUM is a research algorithm. One distinct difference is the treatment of boundary layer clouds, see Sect. 4.2.4.

The DLR algorithm uses threshold techniques to identify broken or semi-transparent clouds. If the clouds are opaque and fully cover the pixel, radiance fitting is used, otherwise radiance ratioing with the $10.8 \mu \mathrm{m}$ window and the $13.4 \mu \mathrm{m}$ $\mathrm{CO}_{2}$ channel is used.

The GSF algorithm starts with an optimal estimation retrieval of the CTP. For high clouds with CTP smaller than $600 \mathrm{hPa}$, this value is the final result. Otherwise radiance fitting is used to retrieve CTP for low clouds.

LAR uses a thresholding technique to detect clouds (Minnis et al., 2008b). COD, cloud phase, REF and effective temperature CET are determined simultaneously using the iterative Visible Infrared Solar-Infrared Split Window Technique (VISST). CTT is determined from CET using a parameterization based on COD for thin clouds (Minnis et al., 2011). For thick clouds, CTT is assumed to be essentially the same as CET. CTT is then matched with the highest pressure (lowest altitude) having the same temperature as a modified NWP temperature profile to estimate CTP (CTH). The temperature profile near the earth's surface is defined using a zonally dependent lapse rate (Minnis et al., 2010). A supplemental 10.8/13.4 $\mu \mathrm{m}$ radiance ratioing technique (Chang et al., 2010) is used to adjust high cloud tops.

UKM uses the radiance ratioing method of Eyre and Menzel (1989) with the $10.8,12.0$ and $13.4 \mu \mathrm{m}$ channels first. If a suitable solution is not found by this method (i.e., if the uncertainty in the radiance ratioing solution is greater 
than a prescribed threshold), then radiance fitting with the $10.8 \mu \mathrm{m}$ channel is employed. Additionally, UKM uses a priori knowledge of the atmospheric stability from the MetOffice model to deal with low-level inversions (Moseley, 2003; Francis et al., 2008). In practice, this means that the radiance ratioing method is primarily chosen for upper-level clouds, and the radiance fitting method with a priory constraints is applied for lower-level clouds. If no solution is found from these methods, UKM uses radiance fitting without any a priory constraints as fall-back solution, but this rarely happens.

OCA and AWG are both optimal estimation retrievals. AWG utilizes the $10.8,12$ and $13.4 \mu \mathrm{m}$ channels, whereas OCA uses all SEVIRI channels except the 3.9 and $9.6 \mu \mathrm{m}$ and simultaneously estimates the cloud phase, CTP, COD and REF of one or in some cases two cloud layers.

The algorithms use different surface albedo data sets: CMS, DLR, MFR, AWG, UKM and GSF make use of albedo data sets derived from MODIS measurements. CMS uses the parameterizations of Masuda et al. (1988) and Salisbury and D'Aria (1992) for ocean and land emissivities, respectively. The DLR uses the parameterization of Cox and Munk (1954a) and Cox and Munk (1954b) for reflectances of the ocean and the emissivities of Seemann et al. (2008). The EUMETSAT algorithms OCA, EUM and MPF use EUMETSAT's SEVIRI Clear Sky Reflectance product (Lutz et al., 2011) and the CIMSS Baseline Fit emissivity database for the IR channels (Seemann et al., 2008). LAR makes use of reflectances and emissivities of Minnis et al. (2008a).

The distinction of aerosols and clouds is critically important for aerosol retrievals. Different techniques of detection and aerosol property remote sensing have been successfully applied to SEVIRI measurements (Brindley and Russell, 2006; Brindley et al., 2012; De Pape and Dewitte, 2008; Li et al., 2007; Parajuli et al., 2013; Romano et al., 2013; Sannazzaro et al., 2014). These algorithms have been validated and inter-compared (Banks and Brindley, 2013; Breon et al., 2011; Schepanski et al., 2012). Due to the frequent occurrence of optically thick clouds dominating the radiative properties of the atmosphere, this distinction is less important to cloud retrievals than to aerosol retrievals, but nevertheless relevant. At the moment none of the SEVIRI cloud retrievals described in this paper has an explicit aerosol cloud discrimination test. However, most of them consider the radiative effect of aerosols. AWG, EUM, GSF, LAR, MPF, OCA and UKM implicitly consider aerosols by using a clear sky reflectance product influenced by the aerosol radiative effect. DLR, CMS and MFR algorithm take care of the effects of aerosols by considering climatologic aerosol loading in their radiative transfer simulations. DLR includes rural aerosol types for continental areas (Shettle, 1989) within the lowest $2 \mathrm{~km}$ of the atmosphere and aerosols with a visibility of $50 \mathrm{~km}$ above. The CMS and MFR algorithms use maritime or continental aerosols of $30 \mathrm{~km}$ or $70 \mathrm{~km}$ horizontal visibility for sea and land, respectively (Derrien and Le Gléau, 2013).

\section{Inter-comparison of SEVIRI retrievals}

First we focus on the CTP, as this property is directly provided by all cloud retrievals, whereas CTH is provided by five algorithms only. Figure 1 shows the CTP derived by the algorithms for 13 June 2008, 13:45 UTC. The zonal distribution of the CTP is comparable for all data sets. High clouds are present in the inter tropical convergence zone (ITCZ). Adjacent to them, low clouds are most common in the marine stratocumulus region between $30^{\circ} \mathrm{S}$ and $30^{\circ} \mathrm{N}$. In the midlatitudes synoptic systems with their frontal structures can be identified. The derived CTP means range from $577 \mathrm{hPa}$ to $424 \mathrm{hPa}$. The smallest mean CTPs (the highest clouds) are retrieved by MFR (424 hPa), CMS (432 hPa) and AWG ( $439 \mathrm{hPa})$; the algorithms showing the largest mean CTPs (the lowest clouds) are EUM (558 hPa) and MPF (577 hPa). Averaging is performed with the logarithm of CTP and afterwards converted into a pressure again. In this way, the mean CTP is more comparable to the mean CTH. Note that the different cloud detection of the algorithms influences the cloud cover and thus the mean CTP. Some algorithms also limit the retrieval domain due to high viewing or solar zenith angles and/or sun glint.

In Fig. 2 some basic statistics of the multi-algorithm ensemble are presented. In Fig. 2a we show the number of algorithms that detect a cloud and provide a CTP value for the observed satellite pixel. In general, the agreement of the cloud detection among the algorithms is good, in particular for the central parts of the cloud systems. However, at the edges of the cloud systems the cloud detection results differ. The ability to detect a cloud decreases when the sub-pixel cloud fraction and/or the COD decreases, see Fig. 2d showing the multi-algorithm ensemble average of the COD. There might also be overestimations of the cloud cover by some algorithms due to misinterpretation of aerosols or cloud free scenes as clouds. In particular, false cloud detection may occur in case of large uncertainties in the surface albedo, emissivity and temperature.

The multi-algorithm average of the CTP is shown in Fig. 2b. The area displayed is limited to regions for which all SEVIRI retrievals detect clouds. Figure $2 \mathrm{c}$ shows the multialgorithm ensemble standard deviation of the logarithm of CTP. To eliminate the influence of different cloud masks, only pixels are shown for which all algorithms provide a retrieval. In the tropics we observe small standard deviations for the cores of deep convective systems, where COD is larger than 10. On the other hand, the standard deviation tends to increase toward the outer boundary of the deep convective systems where their cirrus anvils become thinner. In particular over the tropical Indian Ocean there is an extended area of optically thin clouds with a high standard deviation of CTP. In trade wind cumulus and marine stratocumulus regions the standard deviation is usually smaller than 0.1 . The smallest standard deviations are found in the marine stratocumulus region west of Angola. In these regions the clouds are 

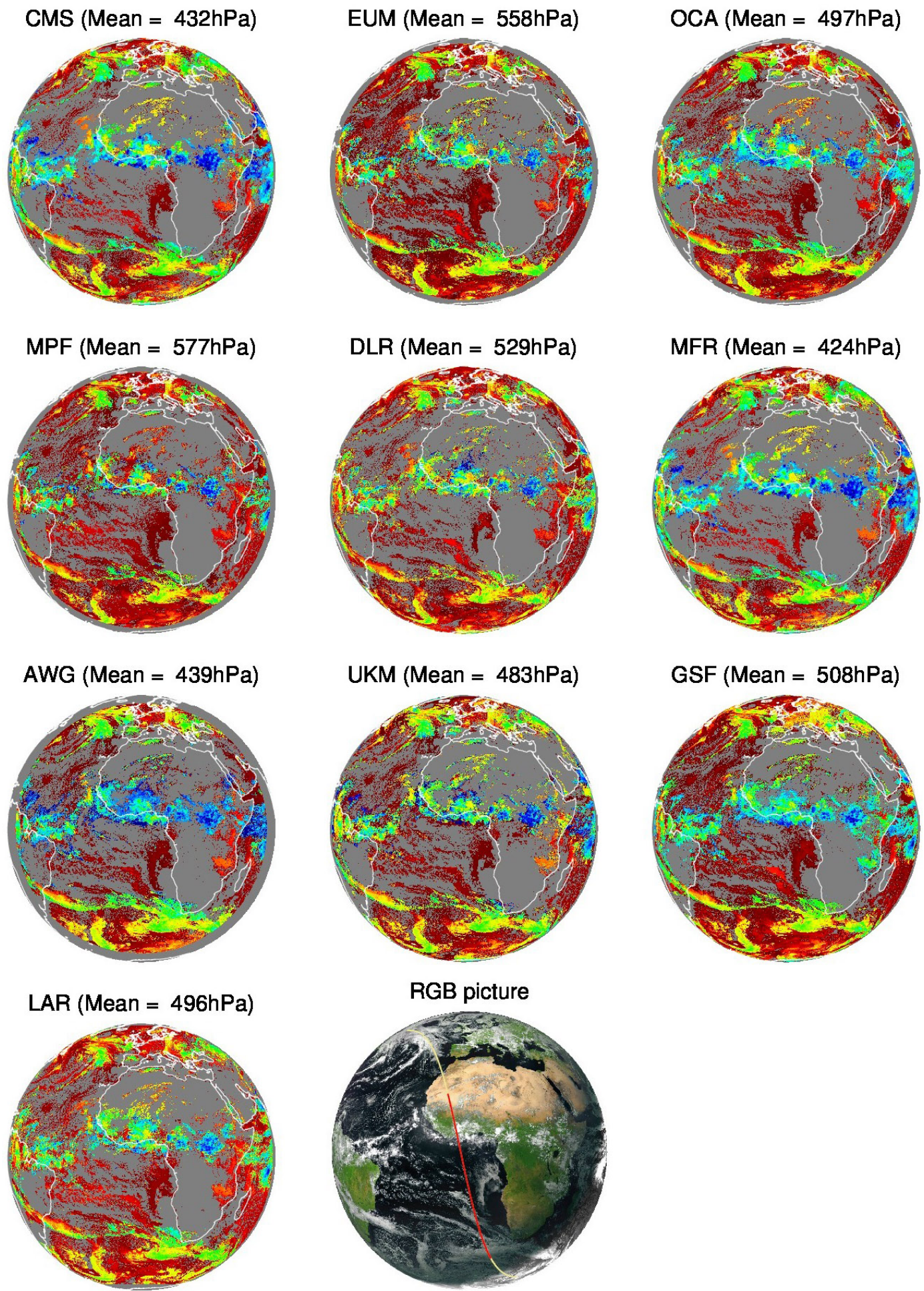

RGB picture

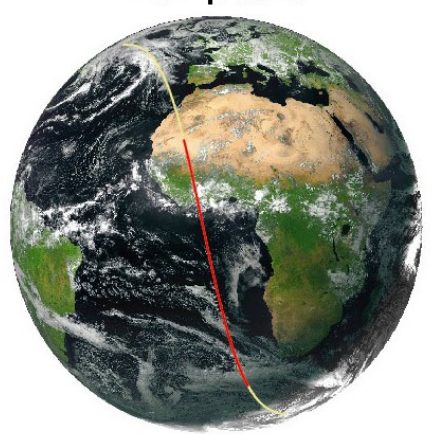

100

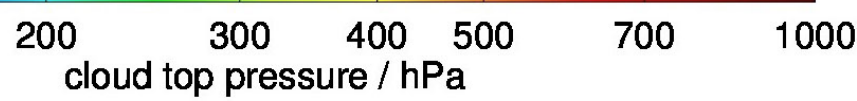

Figure 1. Cloud top pressure (CTP) of ten SEVIRI algorithms for the 13 June 2008, 13:45 UTC. The mean CTP is calculated by averaging the logarithm of the CTP. The last plot shows the corresponding RGB image of the scene. The track of the A-train satellite constellation between 13:45 UTC and 14:00 UTC is indicated as a red line. 

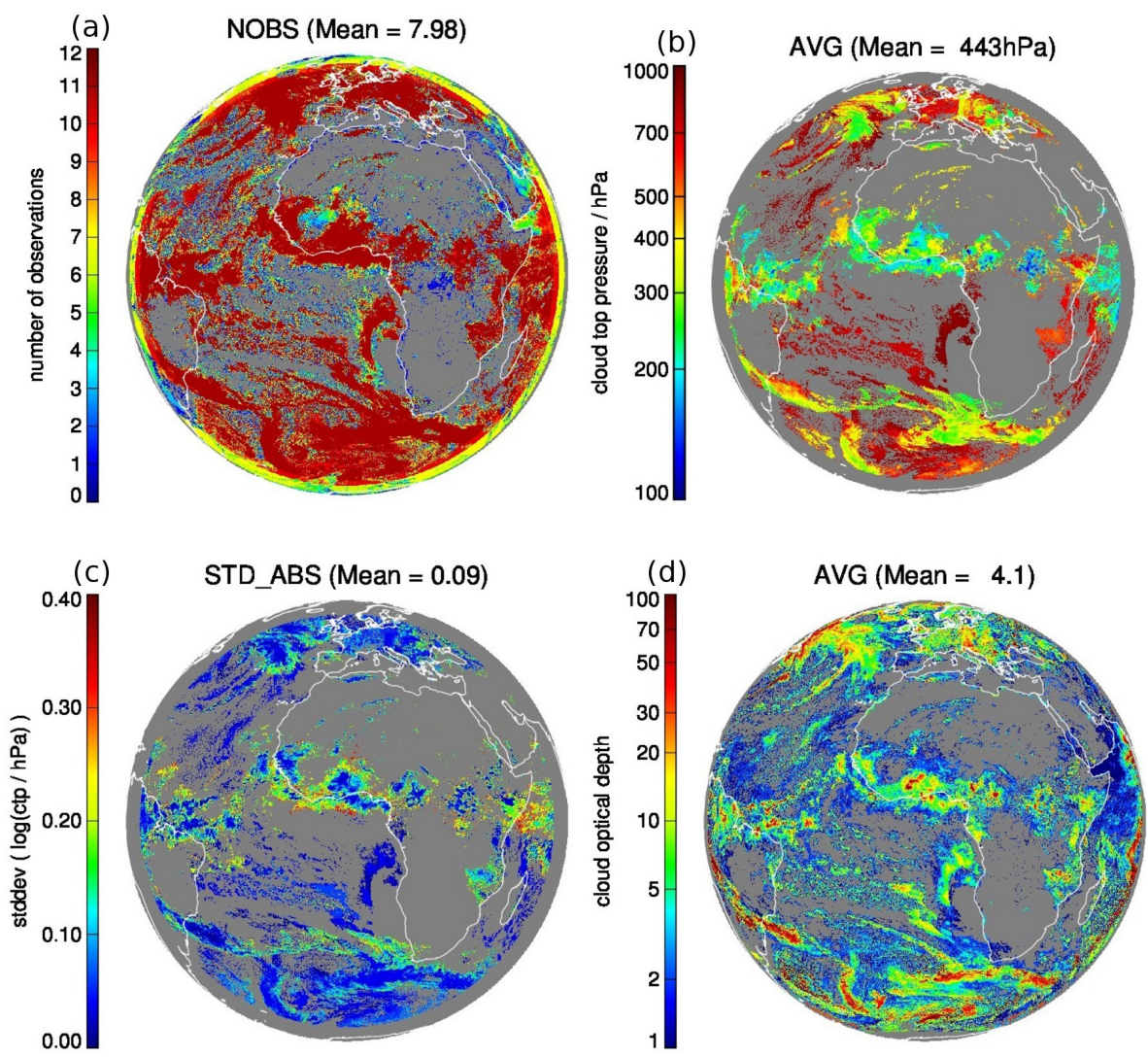

Figure 2. Multi-algorithm ensemble statistics. Panel (a) displays the number of algorithms that provide a CTP value. Panel (b) shows the multi-algorithm average of the cloud top pressure (CTP). Panel (c) shows the standard deviation of the $\log _{10}(\mathrm{CTP})$. In Panel (b) and (c), values are shown for areas only, for which all retrievals detect clouds (common mask) to eliminate effects of different sample sizes. Panel (d) shows the multi-algorithm average of the cloud optical depth (not limited to the common mask). All images are for 13 June 2008, 12:00 UTC.

closest to fulfilling the common retrieval assumption of horizontal homogeneity; the vertical variation of the cloud tops is small and the optical depth is sufficiently high for a precise retrieval of the CTP. In the extratropics there are some regions with large standard deviations: one band at $35^{\circ} \mathrm{S}$ in the South Atlantic and another area in the North Atlantic near the Azores. The latter is located along the outer border of the cirrus associated with a warm front.

In Fig. 3 we investigate the latitudinal average of the CTP for the individual algorithms. The averages are calculated in two ways. In Fig. 3a and b, all available pixels provided by each of the algorithms are used in the averaging. This is called the individual cloud masks. For this case CTP statistics are influenced by both differences in the CTP retrieval methods and cloud detection. To exclude the effect of cloud detection, in Fig. 3c and d the CTP mean is computed using only those pixels that have a retrieved CTP value for all ten data sets. In the following, we refer to this filtering as the common cloud mask. The observed differences can be completely attributed to characteristics of the CTP retrievals.
Looking at Fig. 3c and d, we notice that AWG, OCA, MFR, CMS and GSF tend to yield smaller CTPs, whereas MPF, DLR and LAR tend to produce higher CTPs compared to the average.

The differences between the data sets are larger for the individual than for the common cloud masks, as for the individual mask the samples are different and as the retrieval of cloud properties is often difficult for clouds that are hard to detect. In the tropics the multi-algorithm ensemble average, shown in black, is about $100 \mathrm{hPa}$ higher for the individual than for the common cloud mask. This implies that aboveaverage CTP values are retrieved for pixels that are not identified as clouds by all algorithms. These are mainly broken clouds or optically thin cloud layers having an incorrectly great CTP (low CTH).

In Fig. 3e we investigate the effect of the different cloud detection efficiencies on the relative standard deviation of the multi-algorithm ensemble. The relative standard deviation of the multi-algorithm ensemble is illustrated. The values shown are relative to the latitude dependent multi-algorithm mean. Using the same area of observation (i.e., the common mask), the agreement of the data sets is better than $25 \%$ for 

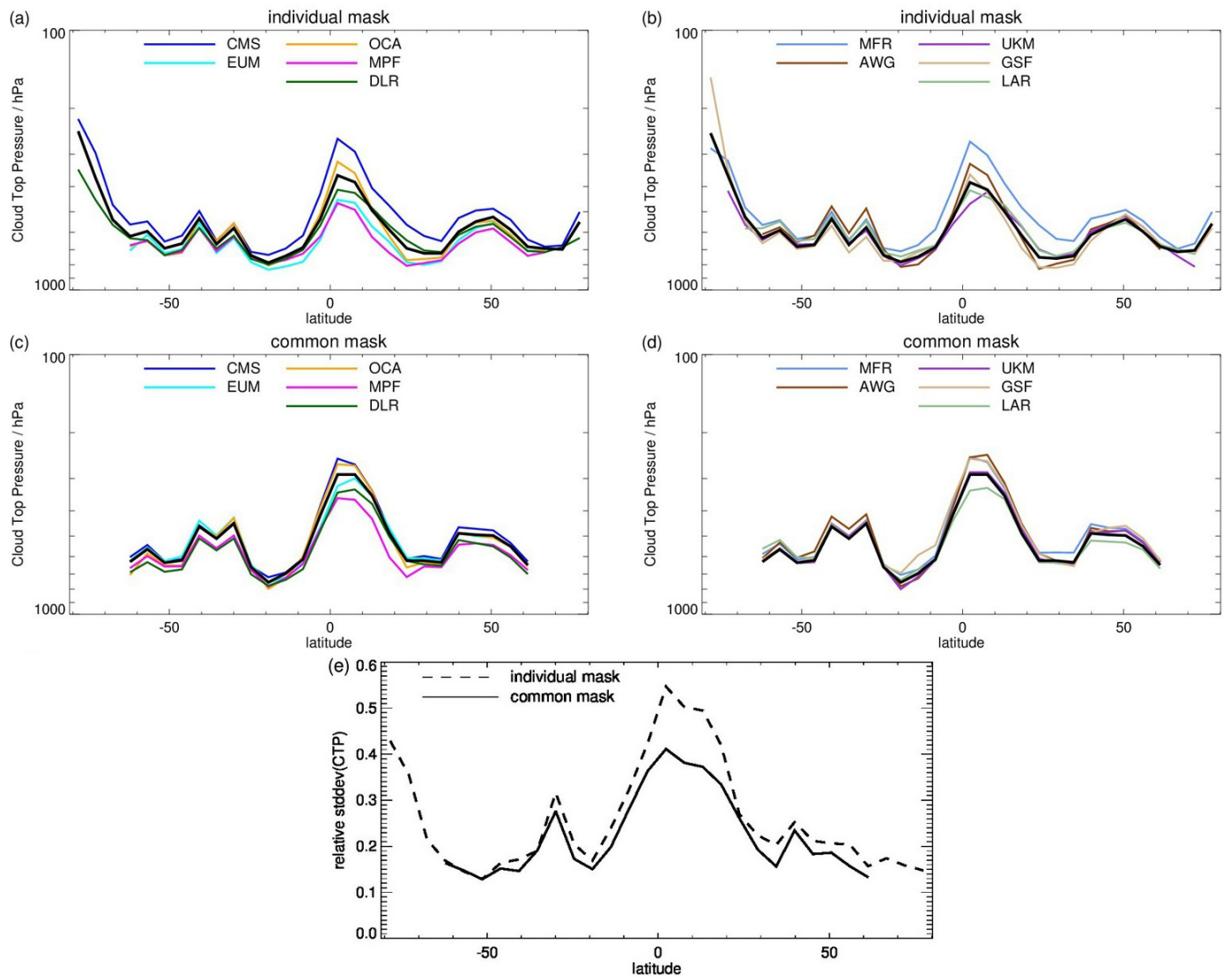

Figure 3. Latitudinal mean of the cloud top pressure of ten algorithms for 13 June 2008, 12:00-15:00 UTC. In panels (a) and (b) the original data sets are used, whereas in panel (c) and (d) the data sets are reduced to observations, for which all ten retrievals detect a cloud and derive a CTP. The black line shows the average of all SEVIRI algorithms. In the lower panel (e) the relative standard deviations of the algorithm ensemble are shown.

most latitudes and better than $40 \%$ in the tropics. The lowest standard deviations of about $15 \%$ are south of $40^{\circ} \mathrm{S}$, at $20^{\circ} \mathrm{S}$, at $30^{\circ} \mathrm{N}$ and north of $50^{\circ} \mathrm{N}$, in agreement with the discussion of Fig. 2. Using the individual cloud masks instead of the common one, the standard deviations are 2 to 5 percentage points larger in the extratropics and about 10 to 15 percentage points larger in the tropics. This indicates that both the retrieval of the correct CTP as well as cloud detection are most challenging for high thin cirrus clouds located mainly in the tropics. At the southernmost edge of the SEVIRI disk, we also observe large standard deviations for the individual cloud masks. As the sun is close to the horizon in this region, not all algorithms provide a retrieval and the retrieval itself is difficult.

In Fig. 4 we investigate the histograms of the CTP, in Fig. $4 \mathrm{a}$ and $\mathrm{b}$ the individual mask and in Fig. $4 \mathrm{c}$ and $\mathrm{d}$ the common mask. All algorithms retrieve a comparable distribution of CTP values with two peaks: a first maximum between the surface and $700 \mathrm{hPa}$ representing boundary layer clouds and a second maximum between 300 and $200 \mathrm{hPa}$ corresponding to high cirrus and deep convective clouds. Midlevel clouds with CTP around $500 \mathrm{hPa}$ occur less frequently.
The occurrence frequency of the boundary layer clouds is strongly reduced when reducing the data set to the common mask. Note the scale of the abscissa indicating the loss of data points when reducing the data sets to the common mask. The cloud frequency distributions with two maxima are in agreement with CTH measurements from MODIS. Chang and $\mathrm{Li}$ (2005a) found a distinct bimodal distribution of CTP peaking at 275 and $725 \mathrm{hPa}$ for high and low clouds, thus leaving a minimum in cloud occurrence frequency in the middle troposphere.

In summary, the SEVIRI algorithms retrieve comparable CTP histograms. The agreement improves when restricting the data sets to the common mask. The greatest deviations are observed for optically thin clouds. A large percentage of these are spreading anvils of deep convective clouds or thin cirrus layers in the tropics. All CTP frequency distributions with respect to height show two maxima related to the boundary layer clouds and clouds near the tropopause. 

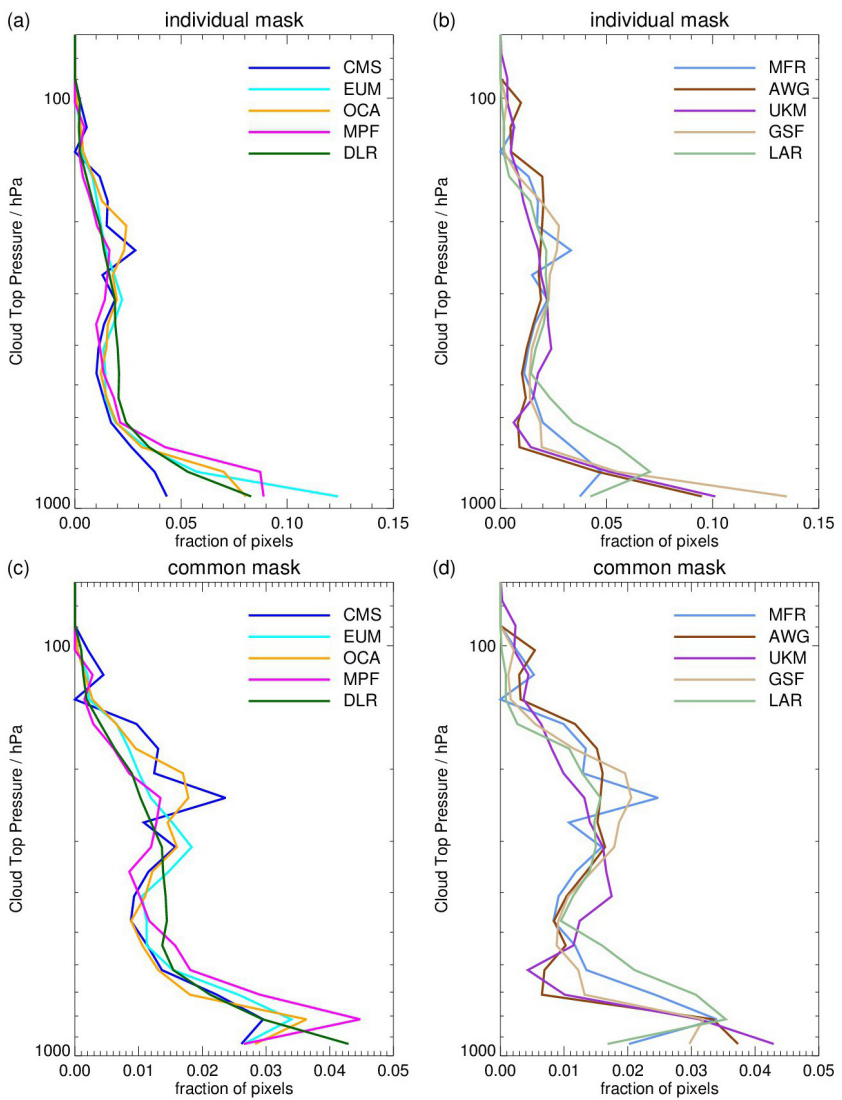

Figure 4. Histograms of the cloud top pressure for 13 June 2008, 12:00-15:30 UTC. In panels (a) and (b) all retrieved values are taken into account, whereas in panels (c) and (d) only observations are taken into account, for which all ten retrievals detect a cloud and derive a CTP.

\section{Comparison with CALIOP and CPR}

To quantify the accuracy of the SEVIRI CTP/CTH retrievals, the SEVIRI data sets are validated against CALIOP and CPR retrieval products listed in Table 5. The CPR and CALIOP data sets have horizontal resolutions of $1.7 \mathrm{~km}$ and the $5.0 \mathrm{~km}$, respectively.

The AVAC-S validation software (Bennartz et al., 2010) is applied to reproject these data sets on the SEVIRI grid. Furthermore, it takes care of the parallax correction for the SEVIRI viewing zenith angle. The AVAC-S software returns either the average of all CPR/CALIOP data points within one SEVIRI pixel or the data point nearest to the SEVIRI pixel center. In this paper averages over SEVIRI pixels are used everywhere. The CALIOP and CPR data are matched with the SEVIRI observations when the time shift is smallest. As SEVIRI scans one disk every $15 \mathrm{~min}$, see Sect. 2.1, the maximum observation time difference is $7.5 \mathrm{~min}$. In case a SEVIRI algorithm only provides CTP and not the CTH, CTP is transformed to CTH using pressure profiles as provided in the ECMWF-AUX product of the CloudSat data
Table 5. List of CPR and CALIOP products used for the validation of the SEVIRI algorithms.

\begin{tabular}{llc}
\hline Sensor & Product & Version \\
\hline CPR & 2B-GEOPROF & 1.1 \\
CPR & 2B-CLDCLASS & 5.3 \\
CPR & 2B-TAU_GRANULE & 5.0 \\
CALIOP & CAL_LID_L1 & 3.01 \\
CALIOP & CAL_LID_L2_CLay & 3.01 \\
CALIOP & CAL_LID_L2_VFM & 3.01 \\
Model & ECMWF-AUX & 5.2 \\
\hline
\end{tabular}

processing center. In this section we concentrate our investigation on the 13 June 2008, 12:00-15:30 UTC, as all ten SEVIRI data sets are available without gaps for this period. During this time the A-train satellite constellation passed the SEVIRI disk three times. The overpass numbers are 11317, 11318 and 11319.

Figure 5 illustrates how the comparison of the SEVIRI, CALIOP and CPR retrievals is accomplished. The first and second panel show the CALIOP backscatter and CPR reflectivity signal, respectively. The CTHs detected by CALIOP and CPR are marked in green and red. In addition to the CTHs of the active instruments, the third and fourth panel show the CTHs derived by the individual SEVIRI algorithms. Large deviations indicate challenging conditions for $\mathrm{CTH}$ retrievals. In Fig. 5 the CALIOP and CPR backscatter signals are used to qualitatively identify different cloud regimes: optically thick clouds, boundary layer clouds, multi-layer and optically thin clouds. For optically thick clouds (green area), the agreement between CALIOP, CPR and the SEVIRI CTHs is very good; the CALIOP CTH is slightly higher than the CPR and SEVIRI CTHs. For multi-layer clouds (red area) either the CPR or CALIOP sensor detect a second cloud layer. Between $0^{\circ}$ and $5^{\circ} \mathrm{N}$ all SEVIRI algorithms capture the upper cloud layer. The deviations of the retrieval results are small on the right hand side, where the CPR backscatter signal indicates an optically thick upper cloud layer. The deviations become larger with a decreasing CPR signal. In the orange regions CALIOP detects an optically thin cloud layer at about $16 \mathrm{~km}$. The sensitivity of CPR is not sufficient to detect this layer; also, most SEVIRI algorithms cannot detect this cloud layer. The blue region marks the boundary layer clouds. The CPR does not detect these clouds as the ground clutter is larger than the cloud signal. Even though the CALIOP attenuated backscatter signal, see upper panel, indicates a fairly constant cloud top, some SEVIRI data sets deviate from the CALIOP CTH. All cloud regimes are discussed in more detail in Sect. 4.2.

\subsection{Overall statistics}

To focus on the characteristics of the CTH retrievals, most statistics are calculated for the common mask in this section. 


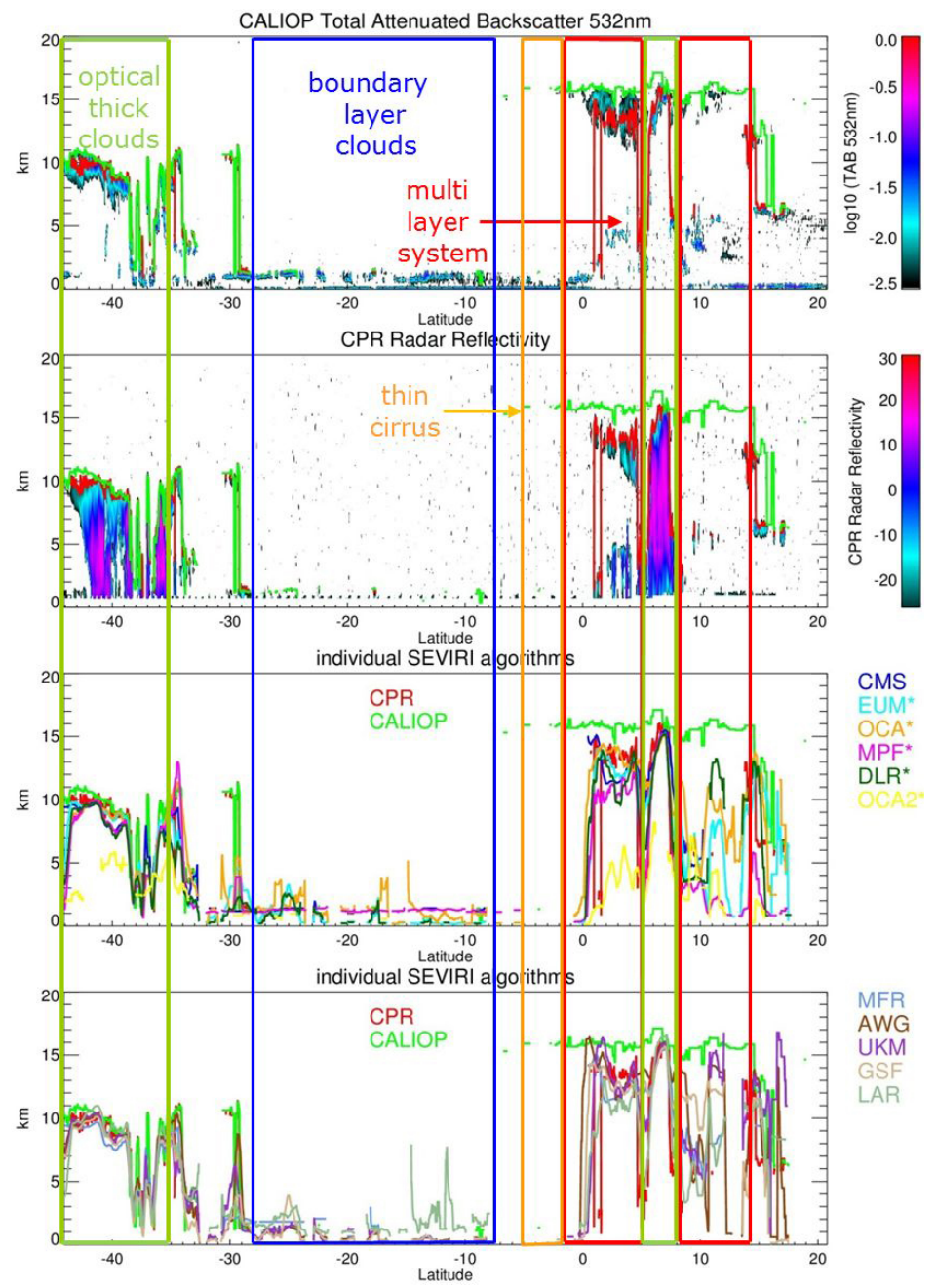

Figure 5. Validation of the SEVIRI cloud top height (CTH) retrievals with CALIOP and CPR for 13 June 2008, 13:45 UTC or A-train overpass 11318. In the first and second panel, the CALIOP backscatter profiles and the CPR reflectivity are shown together with the CTH derived from these instruments. In the third and fourth panel the CTHs derived by the ten SEVIRI algorithms are shown. The OCA algorithm additionally derives the CTH of a possible second cloud layer; this product is labeled as OCA2. Stars at the algorithm name indicate that these algorithms submitted CTP being converted to CTH. The colored boxes roughly indicate different cloud regimes being discussed in more detail in Sect. 4.2.

Here, the common mask refers to pixels, for which all SEVIRI algorithms as well as CALIOP and CPR retrieve a CTP or CTH value, if not indicated differently. Therefore, the cloud detection abilities of all instruments influence the extent of the common mask.

In Fig. 6 we investigate the effect of the common mask filter on the histogram of CTH. In Fig. 6a the histograms of the original CALIOP and CPR measurements are shown as dotted lines. It is possible to detect four relative cloud occurrence maxima as a function of height. Due to different sensitivities of the instruments these maxima are detected at different heights by CALIOP and CPR. For the individual mask the maximal cloud occurrence associated with the tropical tropopause layer (TTL) is detected at 16.5 and $13.5 \mathrm{~km}$ by CALIOP and CPR, respectively, the extratropical tropopause at 10.75 and $10.25 \mathrm{~km}$, the melting layer at $6.25 \mathrm{~km}$ and the boundary layer clouds at $1.25 \mathrm{~km}$. The black line shows the mean of the SEVIRI algorithm histograms. For the individual mask the mean SEVIRI histogram shows a local maximum at $1.25 \mathrm{~km}$ for the boundary layer clouds. Other features are not well defined. A diffuse maximum at $11.75 \mathrm{~km}$ might be attributed to the TTL, the second at $9.5 \mathrm{~km}$ to the extratropical tropopause. The maximum cloud occurrence at $6.25 \mathrm{~km}$ cannot be identified.

Reducing the data sets to the common mask, a large portion of the clouds in the TTL detected by CALIOP are excluded, as SEVIRI and CPR are not able to capture the majority of the optically thin cirrus clouds. The number of boundary layer clouds is also strongly reduced. With decreasing cloud fraction within a pixel, the SEVIRI algorithms tend 

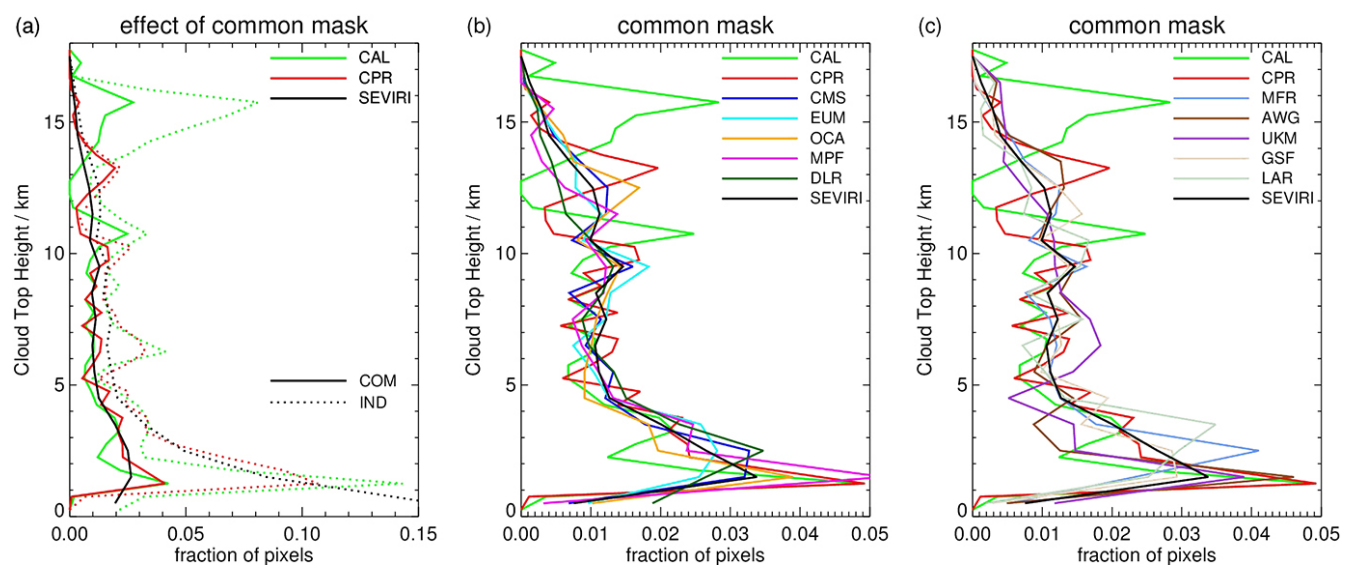

Figure 6. Histograms of the CTH for 13 June 2008, 12:00-15:30 UTC (A-train overpasses 11317-11319). Panel (a) shows the histograms of the complete CALIOP and CPR data set and the average of the SEVIRI algorithm histograms as dotted lines. The histograms using the common mask filtering are shown as solid lines. In panels (b) and (c), the histograms of the individual algorithms are shown using the common mask filtering. For multi-layer cloud situations only the uppermost $\mathrm{CTH}$ is considered.

to classify it as cloud free. If one algorithm does so, the pixel is not included in the common mask. Another reason for the reduction of boundary layer cloud observations for the common mask is the low sensitivity of the CPR near the ground due to ground clutter. Therefore, CPR cannot detect all boundary layer clouds and, by definition, these pixels are excluded from the common mask.

For the common mask, it is still possible to identify the maxima for the TTL, extra-tropical tropopause and boundary layer in the CALIOP and CPR histograms. For the mean SEVIRI histogram, the boundary layer cloud occurrence maximum is clearly defined, but less pronounced for the SEVIRI retrieval average than for the active instrument results. This issue is discussed in more detail in Sect. 4.2.4. The maximum at $9.5 \mathrm{~km}$ is also detectable to some extent.

Figures $6 \mathrm{~b}$ and $\mathrm{c}$ show the histograms of the individual SEVIRI algorithms. There are some differences among the SEVIRI algorithms in reproducing the cloud occurrence maxima, for example, the cloud occurrence maxima of the boundary layer clouds of LAR, MFR and DLR are at higher altitudes than those of the other algorithms.

Figure 7 shows scatter plots of CTH detected by the individual SEVIRI algorithms against CALIOP measurements. Table 6 provides the corresponding differences of the mean values (bias), correlations, normalized standard deviations and root mean square differences (rmsd). Observations are taken into account, when all SEVIRI algorithms as well as the CALIOP retrieval provide CTH values. The scatter plots in Fig. 7 illustrate the capability of the different SEVIRI algorithms to retrieve CTH as a function of the CTH itself. In general, the majority of the scatter points are on the lower right side of the one-to-one line, meaning that the $\mathrm{CTH}$ retrieved by the SEVIRI algorithm is lower than the CALIOP CTH. This is also evident from Table 6. On average all SEVIRI CTHs are $1.05 \mathrm{~km}$ (AWG) to $2.50 \mathrm{~km}$ (DLR) lower
Table 6. Comparison with CALIOP for 13 June 2008, 12:0015:30 UTC. The table shows the difference of SEVIRI minus CALIOP of the mean CTH (bias), correlation between SEVIRI and CALIOP data set (corr), standard deviation of the single data sets divided by that of CALIOP (normalized standard deviation, nstd) and the root mean square difference (rmsd) between the SEVIRI data sets and CALIOP. Pixels are taken into account, for which all SEVIRI algorithms as well as the CALIOP retrieval provide CTH values. Bias and rmsd are given in meter. CALIOP derives a mean CTH of $7852 \mathrm{~m}$ with a standard deviation of $5374 \mathrm{~m}$.

\begin{tabular}{lcccc}
\hline & \multicolumn{3}{c}{ CALIOP, all clouds (2756 pixels) } \\
\cline { 2 - 5 } group & bias & corr & nstd & rmsd \\
\hline CMS & -1668 & 0.850 & 0.808 & 3296 \\
EUM & -1683 & 0.833 & 0.772 & 3432 \\
OCA & -1496 & 0.888 & 0.833 & 2900 \\
MPF & -2468 & 0.781 & 0.747 & 4168 \\
DLR & -2502 & 0.816 & 0.739 & 4011 \\
MFR & -1483 & 0.863 & 0.788 & 3118 \\
AWG & -1049 & 0.896 & 0.856 & 2615 \\
UKM & -1463 & 0.864 & 0.828 & 3079 \\
GSF & -1310 & 0.900 & 0.773 & 2767 \\
LAR & -1743 & 0.766 & 0.743 & 3869 \\
\hline
\end{tabular}

than the CALIOP CTH. Clouds with a CALIOP CTH at about $15 \mathrm{~km}$ are associated with the TTL. CMS, OCA, MFR, AWG and GSF nicely capture these clouds, but are 2 to $3 \mathrm{~km}$ lower than CALIOP. EUM, MPF, DLR, UKM and LAR also have a maximum at about $12 \mathrm{~km}$, but show some more cases of underestimation for these clouds. We note the gap of CALIOP CTHs between $12 \mathrm{~km}$ and $13 \mathrm{~km}$ in the scatter plots, as it is also visible in the histogram of CALIOP CTH, see Fig. $6 \mathrm{~b}$ and c. For CALIOP CTHs between 3 and $11 \mathrm{~km}$ all SEVIRI algorithms generally retrieve CTHs comparable 

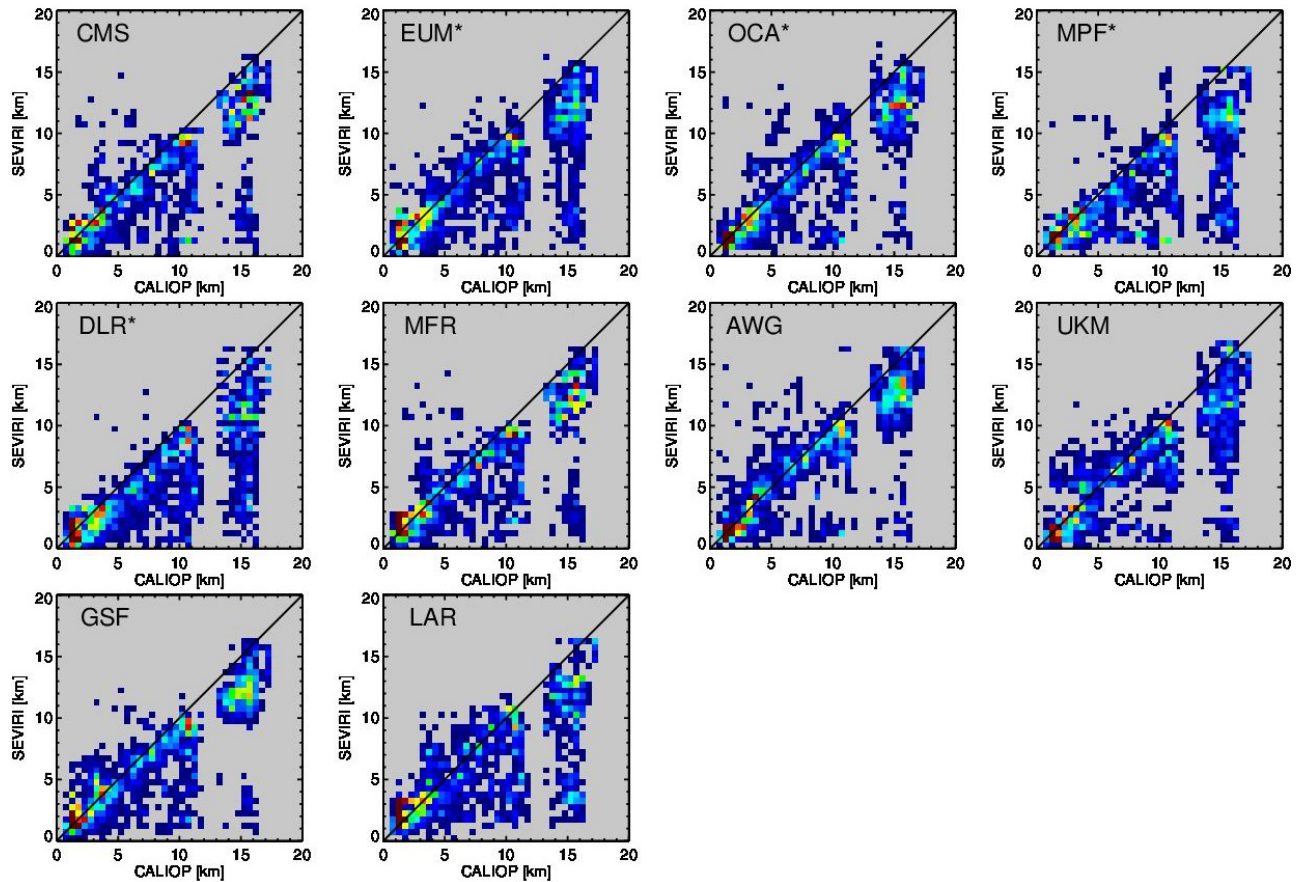

Figure 7. Scatter plots of the cloud top height SEVIRI data sets against the CALIOP data set for 13 June 2008, 12:00-15:30 UTC (Atrain overpasses 11317-11319). Most of the points are on the lower right side showing that the SEVIRI algorithms derive lower CTH than CALIOP

Table 7. Same as Table 6, but for CPR. The mean of CPR observation is $6309 \mathrm{~m}$ and the standard deviation is $4306 \mathrm{~m}$.

\begin{tabular}{lcccc}
\hline & \multicolumn{4}{c}{ CPR, all clouds (2501 pixels) } \\
\cline { 2 - 5 } group & bias & corr & nstd & rmsd \\
\hline CMS & -42 & 0.822 & 0.986 & 2552 \\
EUM & 10 & 0.858 & 0.949 & 2243 \\
OCA & 170 & 0.829 & 1.020 & 2553 \\
MPF & -734 & 0.868 & 0.926 & 2272 \\
DLR & -823 & 0.886 & 0.921 & 2165 \\
MFR & 74 & 0.821 & 0.967 & 2537 \\
AWG & 608 & 0.842 & 1.036 & 2541 \\
UKM & 180 & 0.851 & 1.015 & 2377 \\
GSF & 268 & 0.847 & 0.937 & 2333 \\
LAR & -19 & 0.855 & 0.920 & 2248 \\
\hline
\end{tabular}

to CALIOP although some underestimated and a few overestimated CTHs are seen. The underestimation of CTHs for clouds between 3 and $15 \mathrm{~km}$ is mainly caused by higher sensitivity of CALIOP to optically thin clouds compared to SEVIRI. We discuss this issue in more detail in Sects. 4.2.2 and 4.2.3. For the boundary layer clouds with CALIOP CTHs between 0 and $3 \mathrm{~km}$ some scattering of the SEVIRI results is observed. EUM, MFR, GSF and LAR have a tendency to retrieve higher CTHs than CALIOP. This will be analyzed in Sect. 4.2.4.
Our results are in line with those from previous publications. Holz et al. (2008) investigated the difference between the MODIS and CALIOP CTH in a similar way. They found that the MODIS CTH is $2.6 \pm 3.9 \mathrm{~km}$ lower than the CALIOP data set with $5 \mathrm{~km}$ horizontal resolution (same resolution as we use in this paper). They noted that the global CTH bias between MODIS Collection 5 and CALIOP also depends on the CALIOP product resolution used. They found that CALIOP CTHs are only $1.4 \pm 2.9 \mathrm{~km}$ higher than MODIS Collection 5 CTHs when using the CALIOP $1 \mathrm{~km}$ layer products. For this resolution less CALIOP lidar shots are horizontally averaged and, therefore, the signal-to-noise ratio is lower than that of the $5 \mathrm{~km}$ product meaning the $1 \mathrm{~km}$ CALIOP product is less sensitive to optically thin clouds than the $5 \mathrm{~km}$ product. Hence, the higher spatial resolution is the fewer high clouds are detected by CALIOP and the CTH difference to data sets from passive sensors is smaller. Karlsson and Johansson (2013) investigates the effect of the different cloud detection efficiency of the CALIOP 1 and $5 \mathrm{~km}$ product, too. They suggest a procedure to combine both CALIOP products to obtain a data set for validation the CLARA-A1/PPS retrieval.

Figure 8 and Table 7 show the same comparison, but for CPR instead of CALIOP. Compared to Fig. 7, the scatter plots in Fig. 8 show more points located at the one-to-one line indicating that SEVIRI and CPR have similar sensitivities. Most of the SEVIRI data sets have a significant number of pixels with CTH both higher and lower than the CPR; 

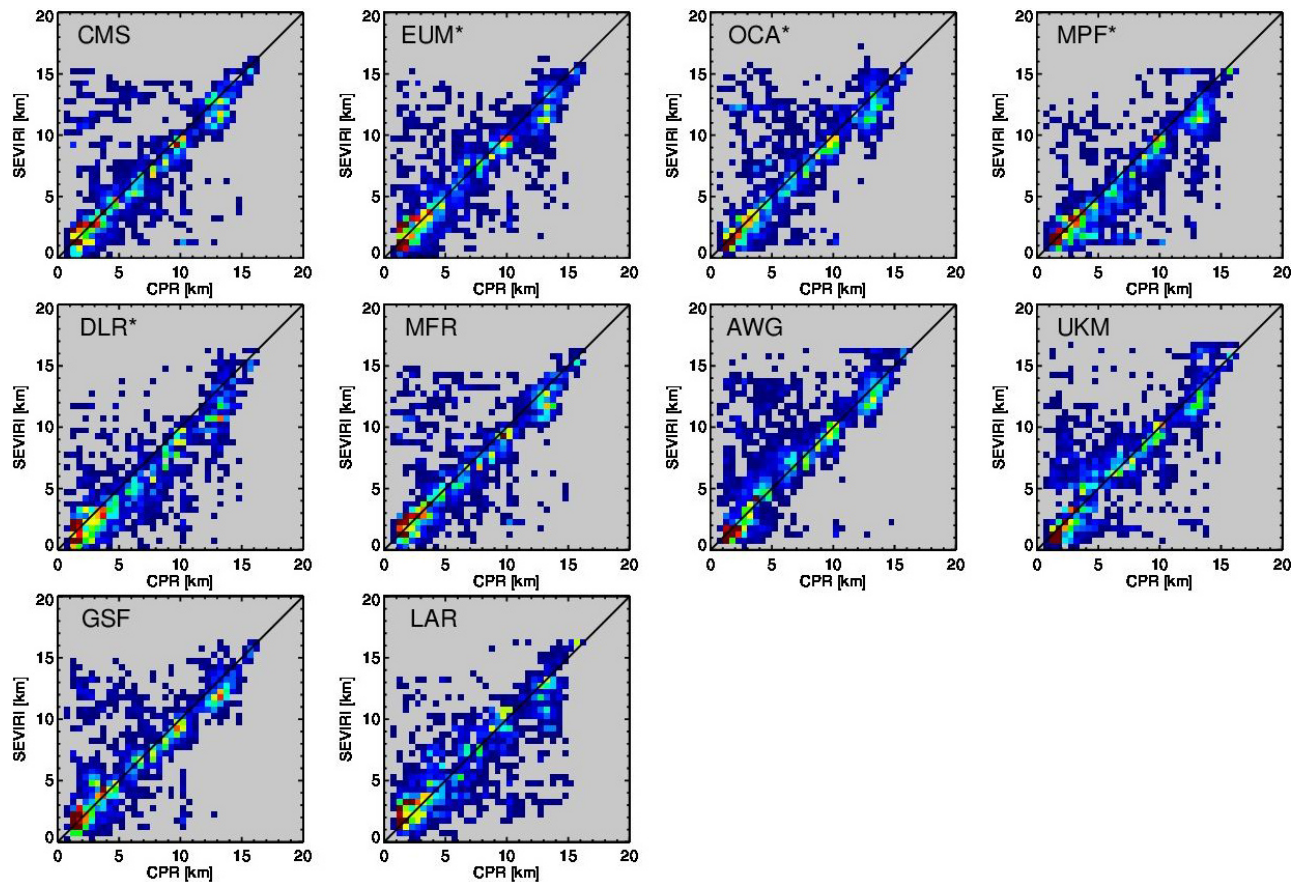

Figure 8. Same as Fig. 7, but for CPR. Pixels are taken into account, when all SEVIRI algorithms as well as the CPR retrieval provide CTH values. In comparison to CALIOP more data points are close to the one-to-one line.

exceptions are OCA, AWG, UKM and GSF detecting mainly higher CTHs than the CPR. The magnitudes of the mean CTH differences between the SEVIRI data sets and CPR are smaller than $0.823 \mathrm{~km}$ for all SEVIRI data sets. The differences are sometimes positive and sometimes negative in contrast to the differences between the SEVIRI data sets and CALIOP being clearly negative for all algorithms.

Figure 9 shows a Taylor diagram (Taylor, 2001) of this evaluation. The radial coordinate is the standard deviation of the SEVIRI data set normalized with the standard deviation of the reference data set (CALIOP or CPR). The angle is the arcus cosine of the correlation coefficient $R$ between the SEVIRI and the reference data sets. The reference point on the $x$ axis marks the point of an ideal agreement (correlation coefficient 1 and same standard deviation as the reference). The distance between the reference point and the marker of the SEVIRI data set is equal to the centered pattern root mean square difference (rmsd) $E^{\prime}$

$E^{\prime}=\left(\frac{1}{N} \sum_{n=1}^{N}\left[\left(s_{n}-\bar{s}\right)-\left(c_{n}-\bar{c}\right)\right]^{2}\right)^{1 / 2}$,

where $s_{n}$ is the SEVIRI data, $c_{n}$ is the comparison data and $N$ is the total number of common data points.

The Taylor plot shows that the correlation coefficients for the comparisons against CALIOP and CPR are in the same range of roughly 0.77 to 0.90 . The standard deviations of the SEVIRI data sets are more comparable to the CPR than to CALIOP as the latter is more sensitive to optically thin

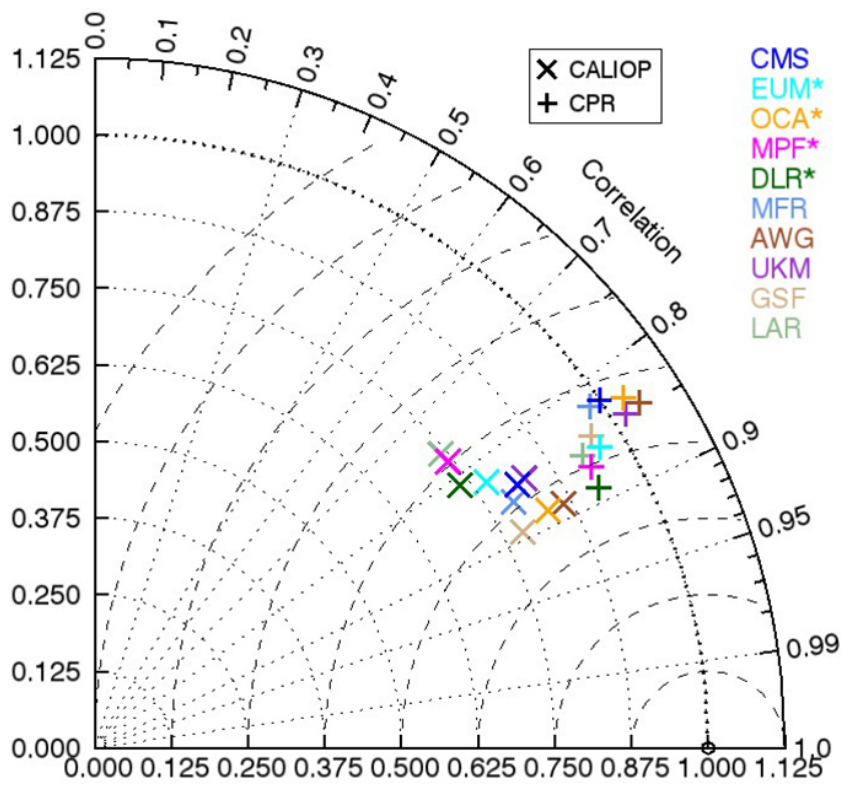

Figure 9. Taylor diagram comparing the SEVIRI data sets with CALIOP and CPR. The Taylor diagram shows the standard deviation of the SEVIRI retrieval divided by those of the reference sensor as radial coordinate and the cosine of the correlation coefficients of these data sets as angle. The correlation coefficients are for both active sensors between 0.77 and 0.90 . The standard deviations of the SEVIRI data sets are smaller than the one of CALIOP and comparable to the one of CPR. 

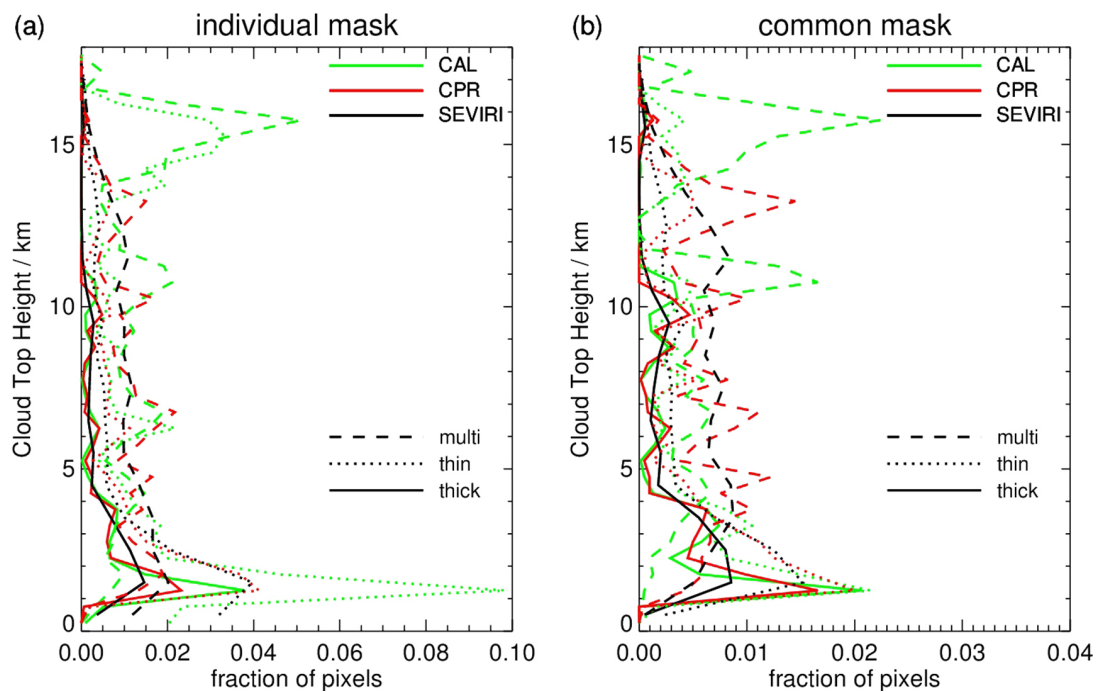

Figure 10. Histograms of the CTH of thick, thin and multi-layer clouds for 13 June 2008, 12:00-15:30 UTC. Panel (a) shows the histograms of the data as provided by the original CALIOP and CPR data sets as well as the mean of the histograms of the unfiltered SEVIRI data sets. In panel (b) only satellite pixels are taken into account for which all data sets provide a value. For multi-layer cloud situations only the uppermost $\mathrm{CTH}$ is considered.

clouds. Using $E^{\prime}$ as the quality measurement, we see that the ranking of the algorithms depends on the reference data set, for example, the DLR algorithm has the lowest (best) $E^{\prime}$ with respect to the CPR, but a large $E^{\prime}$ with respect to CALIOP.

\subsection{Retrieval performance for different cloud regimes}

In this section we investigate the uncertainties of $\mathrm{CTH}$ retrievals for different cloud regimes: thick, thin and multilayer clouds. We analyze how often these cloud regimes occur and how they contribute to the overall deviations between the SEVIRI algorithms and the active sensors. In Sects. 4.2.1 to 4.2.3 there are separate discussions for each of these cloud regimes. In the last Sect. 4.2.4, we focus on clouds in the boundary layer, where possible ambiguities caused by the temperature profile make the conversion from CTT to $\mathrm{CTH}$ difficult.

First, we introduce the three cloud categories. We separate cloud cases into single layer and multi-layer clouds using the CALIOP product Number of Layers Found. The single layer category is further subdivided into optically thin and thick clouds. Clouds with a CALIOP column cloud optical depth at $532 \mathrm{~nm} \tau_{\text {cal }}<3$ are defined as thin and clouds with $\tau_{\text {cal }} \geq 3$ as thick. Table 8 lists our cloud categories. We choose a threshold of 3 to be comparable to the ISCCP cloud classification (Rossow et al., 1985; Rossow and Schiffer, 1999).

Figure 10 shows the histograms of the three cloud categories for 13 June 2008, 12:00-15:30 UTC. Figure 10a shows the histograms of the unfiltered data sets. The same layers with increased cloud occurrence are observed as in Fig. 6, but in this figure information about the cloud
Table 8. Definition of three cloud categories investigated in Sect. 4.2. Single and multi-layer clouds are separated by the CALIOP product Number of Layers Found (NLF). Single layer clouds are further subdivided into optically thin and thick clouds using the CALIOP column cloud optical depth at $532 \mathrm{~nm} \tau_{\text {cal }}$.

\begin{tabular}{lc}
\hline Cloud category & Criteria \\
\hline Single layer thin cloud & $\mathrm{NLF}=1$ and $\tau_{\text {cal }}<3$ \\
Single layer thick cloud & $\mathrm{NLF}=1$ and $\tau_{\text {cal }} \geq 3$ \\
Multi-layer clouds & $\mathrm{NLF}>1$ \\
\hline
\end{tabular}

categories is additionally provided. In the TTL at 15 to $16 \mathrm{~km}$, thin and multi-layer clouds are detected by CALIOP. The CPR captures mainly multi-layer clouds and some of the thin clouds at about $13 \mathrm{~km}$. At the extratropical tropopause at $11 \mathrm{~km}$ both sensors detect primarily multi-layer clouds, at $6.5 \mathrm{~km}$ thin clouds and multi-layer are detected, and in the boundary layer mainly thin and some thick clouds are observed. The high occurrence of thin clouds detected by CALIOP in the boundary layer may be explained by the averaging of CALIOP retrievals over the area of one SEVIRI pixel. The frequent occurrence of optically thin clouds in the boundary layers detected by SEVIRI can partly be caused by misinterpretation of broken clouds, being inhomogeneous on a sub-pixel scale, as thin clouds.

Reducing the data sets to the common mask, multi-layer clouds are less frequently excluded from the data set than optically thin clouds, as the underlying cloud layer facilitates cloud detection by SEVIRI. The cloud occurrence maxima of CALIOP and CPR are also recognizable in the filtered data 
sets. The mean SEVIRI histogram shows maxima of thin and thick cloud occurrences in the boundary layer, but these are less sharp than the corresponding maxima of CALIOP and $\mathrm{CPR}$ at $1.25 \mathrm{~km}$. As primarily single layer clouds are dominant in this region, we conclude that the different shapes of the peak are not due to other cloud layers above the boundary layer clouds, but have to be explained by other reasons like for instance retrieval ambiguities due to temperature inversions, see Sect. 4.2.4. The mean SEVIRI multi-layer CTHs are more or less evenly distributed between 2 and $13 \mathrm{~km}$.

Tables 9 and 10 provide the same statistics as Tables 6 and 7 but are separated into thick, thin and multi-layer clouds. For thick single layer clouds the correlation coefficients are usually greater than 0.95 in comparison to both active instruments. The mean differences to CALIOP and CPR are only a few hundred of meters for most algorithms, but LAR overestimates the CTH compared to both reference data sets by more than $600 \mathrm{~m}$. The root mean square deviations are generally about $1 \mathrm{~km}$.

For optically thin clouds the CTH differences tend to become negative. In particular MPF and DLR retrieve CTHs that are about $1 \mathrm{~km}$ lower than CALIOP and about $600 \mathrm{~m}$ lower than CPR. Most of the correlation coefficients are above 0.92 . The root mean square deviations are between 1.5 and $2.5 \mathrm{~km}$.

The lowest correlations and largest biases are observed for multi-layer clouds. The correlation coefficients are between 0.59 and 0.83 in comparison to CALIOP and between 0.64 and 0.79 in comparison to CPR. The mean SEVIRI CTHs are $2.1 \mathrm{~km}$ to $4.4 \mathrm{~km}$ lower than the mean CALIOP CTH. The biases in comparison to CPR are smaller. We find that MPF and DLR detect average CTHs more than $1 \mathrm{~km}$ lower than CPR, whereas the CTH of AWG is $982 \mathrm{~m}$ higher than CPR.

These results are summarized in the Taylor diagrams for the different cloud categories, see Fig. 11. For optically thick clouds the performance of the SEVIRI retrievals compared to CPR and CALIOP are very similar to each other. The same is true for optically thin clouds, but for multi-layered clouds, the locations of the algorithms in the Taylor plot are different comparing the CALIOP and CPR diagrams.

Figure 12 shows the mean difference and root mean square difference (rmsd) of the CTH between the SEVIRI algorithms and the active sensors as a function of the CALIOP COD $\tau_{\text {cal }}$. Taking all clouds into account, see upper row of Fig. 12, the SEVIRI algorithms retrieve CTHs that are about $1 \mathrm{~km}$ lower than the CALIOP CTH for $\tau_{\mathrm{cal}}>2$. For smaller $\tau_{\text {cal }}$ the SEVIRI CTHs are about 2 to $4 \mathrm{~km}$ lower than CALIOP depending on the algorithm. For $\tau_{\mathrm{cal}}>2$ the average rmsd is about $3 \mathrm{~km}$ and increases to $5 \mathrm{~km}$ for smaller $\tau_{\text {cal }}$.

The second row shows the same statistics, but for single layer clouds only. For $\tau_{\text {cal }}>2$ the bias between the SEVIRI and CALIOP algorithms vanishes and the rmsd is about $1 \mathrm{~km}$. For smaller $\tau_{\text {cal }}$ the bias and rmsd increase to up to $2 \mathrm{~km}$ and $3 \mathrm{~km}$, respectively.
The third row of Fig. 12 shows the results for multi-layer clouds. The bias and rmsd do not systematically depend on $\tau_{\text {cal }}$ representing the COD of all cloud layers up to the COD where the lidar signal is saturated. The bias is about 3 to $4 \mathrm{~km}$ and the rmsd is about 4 to $5 \mathrm{~km}$ with respect to CALIOP.

We note that the bias is larger for the multi-layer clouds than for the thin single layer clouds. One reason for this is the assumption of a single layer cloud made by all SEVIRI retrieval algorithms except OCA and AWG. In theory, radiance ratioing can account for the semi-transparency of optically thin cloud layers and, therefore, can retrieve a correct $\mathrm{CTH}$ with its associated uncertainty (in practice this is not always the case). With a second layer underneath and the assumption of a single layer cloud, the correct CTH cannot be retrieved by definition. The best possible retrieval solution for this case is a CTH lying somewhere between the two cloud layers. Hence, there is a direct reason for a distinct low bias of the CTHs retrieved for the upper cloud layer. A second reason is the reduction of cloud cases by the common mask. For the single layer category a significant fraction of thin cirrus clouds are not captured by at least one SEVIRI algorithm and, therefore, are not included in the common mask data set. Looking at Fig. 10a, we observe that especially the thin clouds at about $15 \mathrm{~km}$ are often excluded by this procedure. On the other hand, for multi-layer clouds the lower cloud layer increases the chance of cloud detection, even though the uppermost cloud layer might be optically very thin. Therefore, a large fraction of multi-layer observations are still included in the common mask data set.

The second and fourth columns of Fig. 12 show the same comparison, but for CPR data. Considering all clouds, the mean SEVIRI CTH is close to the CPR CTH for all $\tau_{\text {cal. }}$ The rmsd is about $2 \mathrm{~km}$ for $\tau_{\text {cal }}>1.5$ and increases up to $4 \mathrm{~km}$ for smaller $\tau_{\text {cal. }}$. For single layer clouds the biases are still small, only MPF shows a tendency to underestimate the CTH for optically thin clouds. The rmsd of single layer clouds is about $50 \%$ of the rmsd of all clouds. The CTH bias with respect to CPR of multi-layer clouds shows no clear dependency on $\tau_{\text {cal }}$. For multi-layer clouds, the mean bias is around $0 \mathrm{~km}$ and the rmsd is between 2 and $4 \mathrm{~km}$, but there are individual characteristics of the SEVIRI algorithms.

\subsubsection{Discussion for optically thick clouds}

To explain the CTH differences between SEVIRI and the reference data, it is important to take the different sensitivities of the satellite sensors into account. CALIOP, being the most sensitive instrument, see Sect. 2.1, is able to detect the CTH close to the physical one. CPR, on the contrary, is less sensitive to clouds with small optical depths. Therefore, it is expected that the CPR CTH is generally below the CALIOP counterpart.

In contrast to the active instruments, the SEVIRI CTH is derived from the observed brightness temperatures. Assuming no scattering and no absorption above the cloud, the 
Table 9. Same as Table 6, but for three cloud regimes: thick, thin and multi-layer clouds. For multi-layer clouds the statistics are given with respect to the uppermost cloud layer. The mean CTHs observed by CALIOP are 4000, 5496 and $11014 \mathrm{~m}$ and the standard deviations are 3497, 4784 and $4461 \mathrm{~m}$ for thick, thin and multi-layer clouds, respectively.

\begin{tabular}{|c|c|c|c|c|c|c|c|c|c|c|c|c|}
\hline \multirow[b]{2}{*}{ group } & \multicolumn{4}{|c|}{ Thick clouds (500 pixels) } & \multicolumn{4}{|c|}{ Thin clouds (968 pixels) } & \multicolumn{4}{|c|}{ Multi-layer clouds (1306 pixels) } \\
\hline & bias & corr & nstd & rmsd & bias & corr & nstd & rmsd & bias & corr & nstd & rmsd \\
\hline CMS & 6 & 0.959 & 0.914 & 1003 & -596 & 0.928 & 0.888 & 1890 & -3098 & 0.721 & 0.917 & 4464 \\
\hline EUM & 203 & 0.959 & 0.914 & 1020 & -513 & 0.925 & 0.855 & 1917 & -3267 & 0.689 & 0.876 & 4670 \\
\hline OCA & -117 & 0.969 & 0.945 & 873 & -643 & 0.941 & 0.893 & 1762 & -2651 & 0.783 & 0.920 & 3885 \\
\hline MPF & -196 & 0.981 & 0.918 & 745 & -1068 & 0.884 & 0.824 & 2490 & -4359 & 0.642 & 0.881 & 5641 \\
\hline DLR & -257 & 0.967 & 0.889 & 970 & -1039 & 0.924 & 0.863 & 2120 & -4435 & 0.698 & 0.841 & 5503 \\
\hline MFR & 154 & 0.954 & 0.876 & 1095 & -393 & 0.928 & 0.859 & 1852 & -2923 & 0.755 & 0.895 & 4182 \\
\hline AWG & 140 & 0.957 & 1.017 & 1040 & -208 & 0.944 & 0.952 & 1586 & -2128 & 0.794 & 0.897 & 3475 \\
\hline UKM & 75 & 0.952 & 1.014 & 1090 & -517 & 0.923 & 0.946 & 1917 & -2756 & 0.744 & 0.869 & 4095 \\
\hline GSF & 334 & 0.972 & 0.905 & 914 & -159 & 0.943 & 0.833 & 1688 & -2779 & 0.834 & 0.874 & 3715 \\
\hline LAR & 624 & 0.947 & 0.979 & 1291 & -394 & 0.899 & 0.830 & 2154 & -3643 & 0.591 & 0.854 & 5253 \\
\hline
\end{tabular}

Table 10. Same as Table 9, but for CPR. For clarification the same criteria using CALIOP products are applied for separation of the cloud regimes. The mean CTHs observed by CPR are 4289, 5208 and $7919 \mathrm{~m}$ and the standard deviations are 3480,4236 and $4050 \mathrm{~m}$ for thick, thin and multi-layer clouds, respectively.

\begin{tabular}{|c|c|c|c|c|c|c|c|c|c|c|c|c|}
\hline \multirow[b]{2}{*}{ group } & \multicolumn{4}{|c|}{ Thick clouds (445 pixels) } & \multicolumn{4}{|c|}{ Thin clouds (918 pixels) } & \multicolumn{4}{|c|}{ Multi-layer clouds (1157 pixels) } \\
\hline & bias & corr & nstd & rmsd & bias & corr & nstd & rmsd & bias & corr & nstd & rmsd \\
\hline CMS & 38 & 0.959 & 0.928 & 987 & -127 & 0.929 & 0.990 & 1593 & -28 & 0.639 & 0.992 & 3425 \\
\hline EUM & 182 & 0.966 & 0.940 & 915 & -66 & 0.926 & 0.956 & 1602 & -16 & 0.724 & 0.936 & 2921 \\
\hline OCA & -99 & 0.968 & 0.970 & 874 & -216 & 0.930 & 1.000 & 1595 & 551 & 0.646 & 0.979 & 3414 \\
\hline MPF & -177 & 0.981 & 0.940 & 706 & -605 & 0.920 & 0.928 & 1764 & -1067 & 0.767 & 0.957 & 2911 \\
\hline DLR & -284 & 0.969 & 0.916 & 927 & -644 & 0.946 & 0.975 & 1516 & -1192 & 0.785 & 0.916 & 2828 \\
\hline MFR & 128 & 0.953 & 0.901 & 1071 & 10 & 0.924 & 0.966 & 1633 & 81 & 0.643 & 0.973 & 3376 \\
\hline AWG & 195 & 0.964 & 1.038 & 984 & 291 & 0.923 & 1.050 & 1741 & 982 & 0.675 & 0.953 & 3340 \\
\hline UKM & 86 & 0.958 & 1.036 & 1035 & -59 & 0.922 & 1.054 & 1730 & 363 & 0.702 & 0.941 & 3062 \\
\hline GSF & 311 & 0.979 & 0.930 & 791 & 244 & 0.928 & 0.926 & 1596 & 250 & 0.694 & 0.932 & 3078 \\
\hline LAR & 639 & 0.952 & 1.005 & 1257 & 43 & 0.915 & 0.930 & 1705 & -345 & 0.743 & 0.923 & 2828 \\
\hline
\end{tabular}

radiance at the top of atmosphere $I_{v}$ can be derived by integration of the Schwarzschild equation (Sherwood et al., 2004):

$I_{v}=\int_{0}^{\infty} B_{v}(\tau) e^{-\tau} \mathrm{d} \tau$.

By assuming that the Planck radiation $B_{v}(\tau)$ varies linearly with the $\operatorname{COD} \tau$, it may be inferred from this equation that $I_{v}=B_{v}(\tau=1)$ which means that the CTT (and subsequently the CTH) derived from the measured radiance $I_{v}$ is representative of a level at an optical depth of $\tau=1$ below the actual CTH. This is not to say that it is not possible to detect clouds with an optical depth smaller than 1 with passive imagers: the detection limits are estimated to be about 0.1 to 0.3 depending on the algorithm. Taking scattering into account, Sherwood et al. (2004) states that for optically thick clouds the $10.8 \mu \mathrm{m}$ signal seen by passive imagers corresponds to the temperature at a level located at an optical depth of 1 to 3 measured from the cloud top. The geometric height of this level depends on the ice or liquid water content and effective particle size in the upper layers of the cloud (Minnis et al., 2008a). Because water contents are typically much smaller for ice clouds as compared to liquid clouds, the difference between the effective and physical top heights of the clouds is expected to be much smaller for liquid than for ice clouds.

Most SEVIRI algorithms treat optically thick clouds as opaque bodies or, in other words, as if they were geometrically infinitely thin. But as the measured radiance is emitted from within the upper parts of the cloud, the retrieved CTH detected by SEVIRI is a radiatively effective altitude; hence, the radiatively effective $\mathrm{CTH}$ is expected to be lower than the CTH detected by CALIOP. This was also recognized in previous comparison studies. Minnis et al. (2008b) found that the CTH detected by CERES-MODIS is $1.58 \pm 1.26 \mathrm{~km}$ lower than CALIOP measurements for optically thick ice clouds. Menzel et al. (2008) established that the CTH of 

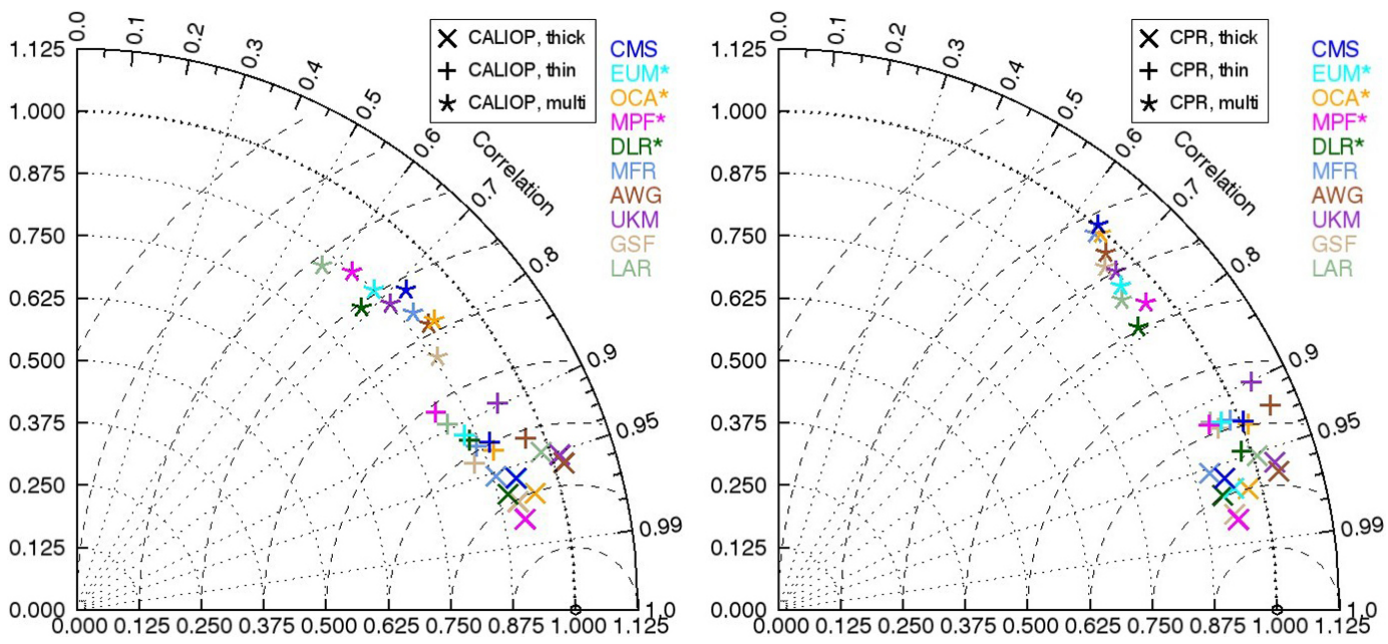

Figure 11. Taylor diagram for CALIOP (left) and CPR (right). Similar to Fig. 9, but the statistics are calculated separately for optically thick $\left(\tau_{\mathrm{cal}} \geq 3\right)$ and thin $\left(\tau_{\mathrm{cal}}<3\right)$ single layer clouds as well as for multi-layer clouds.
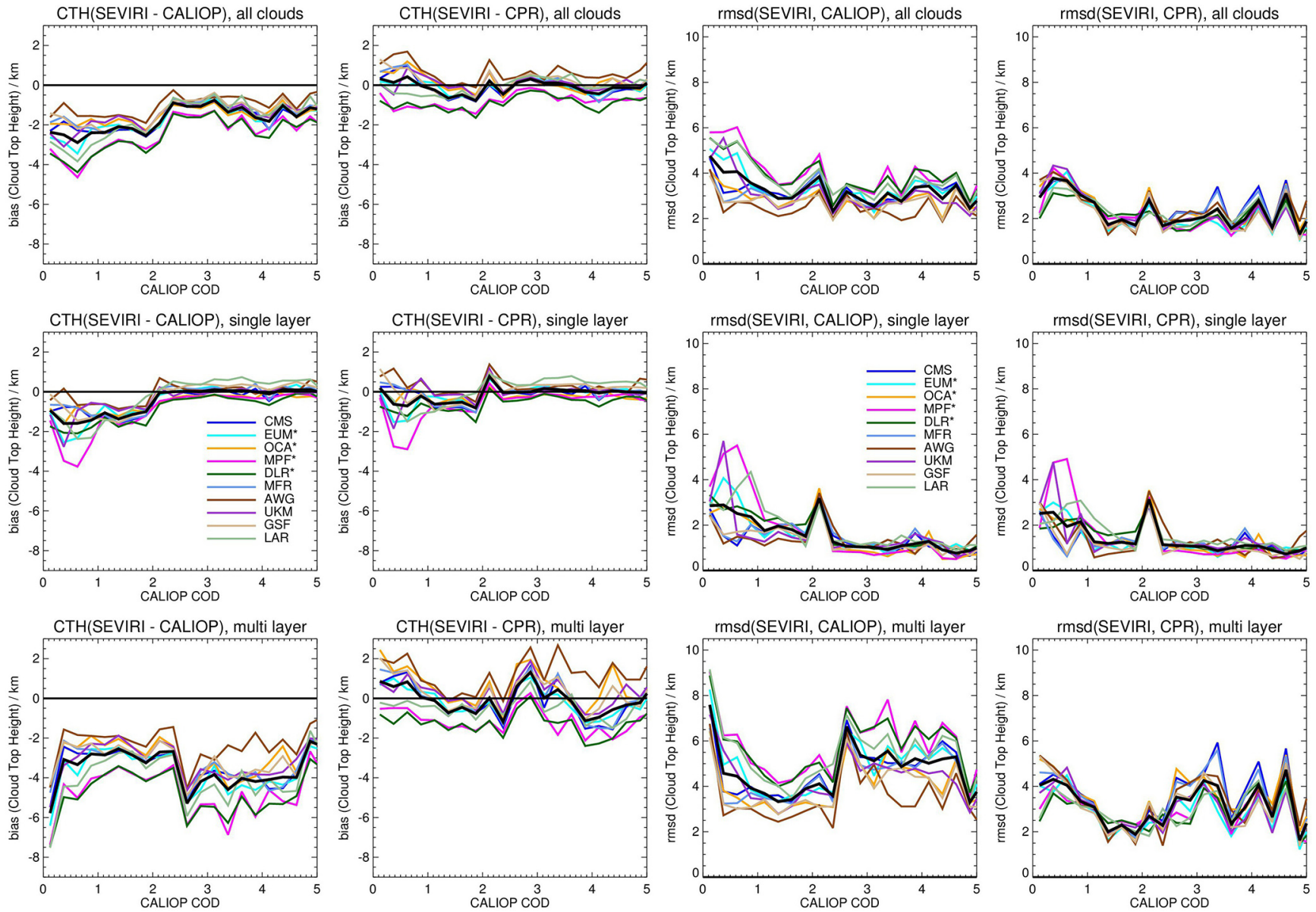

Figure 12. Differences and root mean square deviations (rmsd) of the CTH between the SEVIRI and CALIOP and CPR in dependence of the CALIOP column cloud optical depth for 13 June 2008, 12:00-15:30 UTC. The uppermost row shows the results for all clouds, the second row for single layer and the third row for multi-layer clouds. The first and third columns show the comparison to CALIOP CTH, the second and fourth ones the comparison to CPR CTH. All statistics are calculated for the common mask. 
Table 11. Same as Table 6, but for clouds with a CALIOP CTH smaller than $3.25 \mathrm{~km}$ only. Pixels are taken into account, for which all SEVIRI algorithms as well as the CALIOP retrieval provide CTH values. This comparison is for 13 June 2008, 12:0015:30 UTC. The mean CTH retrieved from CALIOP is $1806 \mathrm{~m}$ and the standard deviation is $661 \mathrm{~m}$.

\begin{tabular}{lcccc}
\hline & \multicolumn{3}{c}{ CALIOP, low clouds (819 pixels) } \\
\cline { 2 - 5 } group & bias & corr & nstd & rmsd \\
\hline CMS & 139 & 0.400 & 1.884 & 1162 \\
EUM & 345 & 0.326 & 1.549 & 1078 \\
OCA & -41 & 0.605 & 1.387 & 738 \\
MPF & 51 & 0.590 & 1.194 & 668 \\
DLR & -20 & 0.255 & 1.174 & 882 \\
MFR & 458 & 0.322 & 1.858 & 1277 \\
AWG & 32 & 0.395 & 1.682 & 1046 \\
UKM & 44 & 0.479 & 2.029 & 1178 \\
GSF & 621 & 0.567 & 1.791 & 1156 \\
LAR & 587 & 0.310 & 1.355 & 1103 \\
\hline
\end{tabular}

MODIS collection 5 agrees with lidar measurements within $50 \mathrm{hPa}$ or $1 \mathrm{~km}$ for high, optically thin cirrus and mid-level water clouds (both single layer). Sherwood et al. (2004) observed that the CTH of deep convective clouds derived from GOES- 8 observations is 1 to $2 \mathrm{~km}$ below measurements of the airborne Cloud Physics Lidar (CPL) during the CRYSTAL-FACE campaign.

Looking at the statistics for optically thick clouds in Table 9, we observe that the mean SEVIRI CTH is lower than that of CALIOP for OCA, MPF and DLR. But for the other algorithms the mean CTH is higher than CALIOP. Especially LAR overestimates the CTH for thick clouds mainly as a result of overestimating low cloud heights, see Tables 11 and 12.

All SEVIRI retrievals aim for a small total CTH bias. So it is possible that an algorithm overestimates the CTH for thick clouds so that the negative bias of optically thin and multilayer clouds is partly balanced in the overall bias. There are also other possible reasons for the observed differences between the CTH retrievals of passive and active sensors, such as different viewing geometries and different fields of view as well as the effect of the cloud top structure (Dong et al., 2008). These uncertainties may create underestimation as well as overestimation, hence, they partly compensate each other in their effect on the mean bias, whereas the differences between the effective and physical CTH does not.

\subsubsection{Discussion for optically thin clouds}

The retrieval of the CTH is more complicated for semitransparent than for opaque cloud situations. The thermal emission from the surface and the atmosphere below the cloud contribute to the observed thermal radiance, see Eq. (5). Therefore, the cloud emissivity, the emission of the
Table 12. Same as Table 11, but for CPR. For clarification, the identification of low clouds is done with the CALIOP CTH. Pixels are taken into account, for which all SEVIRI algorithms as well as the CALIOP and CPR retrieval provide CTH values. The mean CTH retrieved by CPR is $1996 \mathrm{~m}$ and the standard deviation is $726 \mathrm{~m}$.

\begin{tabular}{lcccc}
\hline & \multicolumn{3}{c}{ CPR, low clouds (726 pixels) } \\
\cline { 2 - 5 } group & bias & corr & nstd & rmsd \\
\hline CMS & 119 & 0.380 & 1.783 & 1225 \\
EUM & 274 & 0.381 & 1.526 & 1102 \\
OCA & -123 & 0.621 & 1.368 & 794 \\
MPF & -17 & 0.638 & 1.046 & 632 \\
DLR & -155 & 0.295 & 1.065 & 904 \\
MFR & 338 & 0.326 & 1.759 & 1291 \\
AWG & 46 & 0.433 & 1.682 & 1118 \\
UKM & -22 & 0.467 & 1.818 & 1171 \\
GSF & 534 & 0.547 & 1.683 & 1155 \\
LAR & 507 & 0.343 & 1.342 & 1116 \\
\hline
\end{tabular}

surface and atmosphere below the cloud influence the radiative transfer. For the simultaneous retrieval of CTH and the cloud emissivity, it is necessary to use at least two thermal channels. It is expected that the uncertainty of the retrieved $\mathrm{CTH}$ increases with decreasing emissivity of the cloud, as the difference between clear and cloudy sky radiance $I_{\nu}-I_{\nu}^{\text {clr }}$ used for the CTH retrieval becomes small, see Eq. (12). Uncertainties arise not only from the assumptions made for the water vapor profile as well as the surface temperature and emissivity, but also from instrument noise, spectral response function errors and radiative model approximations (Menzel et al., 2008).

Smith and Platt (1978) noted that on average the CTH derived by $\mathrm{CO}_{2}$ slicing is located at the height corresponding to half of the optical thickness for optically thin clouds. During the validation of the SEVIRI retrievals, we noticed cases of optically thin clouds, where retrieved SEVIRI CTHs lie far below the cloud's mid-level height and sometimes even below the cloud base. This has also been observed in other studies. It was found that CTH differences between passive instruments and lidar retrievals may be as large as $3 \mathrm{~km}$ for thin cirrus clouds, in particular for geometrically thick but tenuous clouds (Holz et al., 2006, 2008; Chang et al., 2010). This issue seems to affect many algorithms and needs to be researched in more detail.

\subsubsection{Discussion for multi-layer clouds}

The retrieval problems of multi-layer clouds are similar to that of optically thin clouds, but additionally the properties of the lower cloud layer are unknown. Assuming a single layer in multi-layer cloud situations results in a retrieved CTH that is representative of a radiative mean between the two cloud layers (Baum and Wielicki, 1994). Looking at the multi-layer segment between $1^{\circ} \mathrm{S}$ and $5^{\circ} \mathrm{N}$ in Fig. 5, the CPR retrieves 


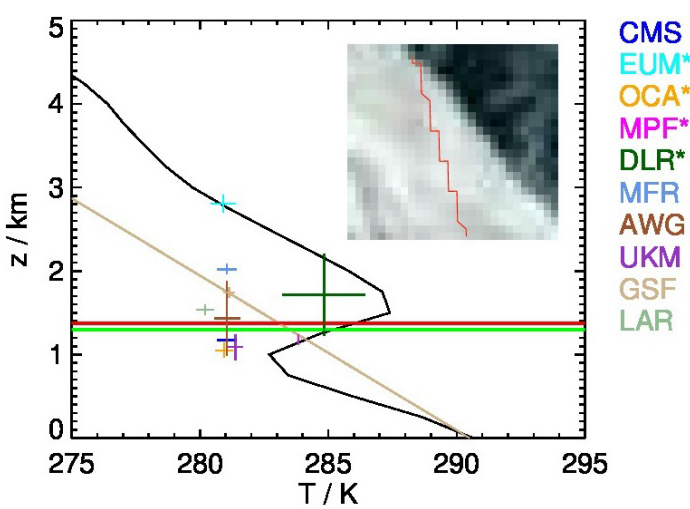

Figure 13. Cloud top height vs. temperature for the homogeneous marine stratocumulus region. The crosses mark the results of the different SEVIRI algorithms. The length of the lines mark the standard deviation of these properties. The chosen track is illustrated as RGB in the upper right corner. The green and red line mark the cloud top height of CALIOP and CPR, respectively. The black line shows the temperature profile as provided by the ECMWFAUX product. Groups that did not submit a cloud top height, but a cloud top pressure (that we converted to cloud top height using ECMWF data) are marked with a star *. The temperature profile constructed with a climatological temperature gradient used by the GSF retrieval is shown as brown line.

a CTH about $2 \mathrm{~km}$ below the CALIOP measurement. Most of the SEVIRI results are similar or slightly below the CPR measurement. The spread of the SEVIRI results increases toward the south, as the optical depth becomes smaller in this direction. These results are consistent with findings from Baum and Wielicki (1994), who investigated the CTH error caused by multi-layer systems using HIRS measurements. They found that the CTP is overestimated (CTH is underestimated) in all cases and that errors tend to increase for decreasing effective amount of the upper cloud layer.

There is one retrieval in our study that retrieves the properties of a possible second cloud layer. The OCA algorithm (Watts et al., 2011) rejects the single layer solution in case that the residual cost function of the optimal estimation retrieval is too large and starts another optimal estimation retrieval, in which the cloud top temperature of the lower cloud layer is added to the state vector. In Fig. 5 the second CTH, labeled as OCA2, follows closely the CTH of the lower layer as indicated by the CPR backscatter signal. Due to the improved modeling of the thermal emission below the uppermost cloud layer, the OCA algorithm also provides good results for the upper cloud layer. Looking at Figs. 9 and 11, we find that the OCA retrieval is in good agreement with CALIOP and CPR, but some other algorithms using single layer assumptions are comparable. The AWG algorithm takes care of multi-layer situations, too, but in a simpler way. If the AWG cloud typing detects multi-layered clouds, an opaque lower cloud is inserted at a height determined from surrounding unobscured low cloud retrievals.
In recent publications several approaches have been suggested to detect multi-layer cloud situations (Pavolonis and Heidinger, 2004; Chang and Li, 2005b; Minnis et al., 2007; Chang et al., 2010; Joiner et al., 2010; Wind et al., 2010; Watts et al., 2011, and references therein). Some of these methods are not directly applicable to SEVIRI observations as not all used satellite channels are available. But, nevertheless, they are inspiring examples for the further development of SEVIRI retrievals.

\subsubsection{Low clouds}

In this section clouds in the boundary layer are discussed including marine stratocumulus and trade wind cumulus clouds. As we discussed in Sect. 4.2.1, the radiatively effective CTH is below the physical one. Dong et al. (2008) estimate that the effective CTH is located about $100 \mathrm{~m}$ to $500 \mathrm{~m}$ below the cloud top for typical liquid water contents of a boundary layer cloud. Looking at Tables 11 and 12, the CTHs of the OCA and DLR algorithms are slightly lower than CALIOP. The overestimation of MFR, GSF and LAR can not be explained by the difference of effective and physical CTH, but by possible retrieval ambiguities caused by the temperature inversions as discussed in this section.

Tables 11 and 12 provide the statistics for clouds with a CALIOP CTH lower than $3.25 \mathrm{~km}$. As we define boundary layer clouds using the CALIOP CTH (and do not restrict the SEVIRI results to this height range), it is expected that the correlation coefficients are smaller than in the overall statistics in Tables 6 and 7. Another consequence is that the standard deviations of the SEVIRI data sets are larger in comparison to the CALIOP data set. Most of the SEVIRI algorithms derive a mean CTH larger than the CALIOP and CPR measurements, especially GSF, LAR and MFR. The correlation coefficients are between 0.255 (DLR) and 0.605 (OCA) for CALIOP and between 0.295 (DLR) and 0.638 (MPF) for CPR. Most rmsd values are somewhat larger than $1 \mathrm{~km}$, whereas the ones for MPF, OCA and DLR are smaller than $1 \mathrm{~km}$ for both CALIOP and CPR.

In Fig. 13 we take a closer look at a homogeneous maritime boundary layer cloud to investigate this overestimation. The track is the southernmost part of the boundary layer area marked in blue in Fig. 5 ranging from $25.95^{\circ} \mathrm{S}$ to $25.20^{\circ} \mathrm{S}$. The CALIOP and CPR measurements indicate that the cloud top is very flat. The average CTHs detected by CALIOP and CPR are 1.3 and $1.4 \mathrm{~km}$, respectively. For this particular case, most of the SEVIRI algorithms derive a CTT of about $281 \mathrm{~K}$, but the retrieved CTHs differ by as much as $1.8 \mathrm{~km}$. For the conversion of the observed brightness temperature to a $\mathrm{CTH}$, assumptions about the temperature profile have to be made.

In the following, we discuss the challenges of the $\mathrm{CTH}$ retrieval of low clouds in general terms. First, the conversion from temperature to height may be ambiguous in the case of temperature inversions (e.g., Holz et al., 2008, Fig. 11). A commonly used, pragmatic approach is to choose the first 
height as CTH, where the observed CTT matches with the atmospheric temperature, going through the temperature profile from the surface upwards (bottom-up approach). This method might lead to large underestimation of the CTH. Vice versa the top-down approach might lead to a large overestimation. Second, even small uncertainties in the atmospheric temperature profiles may lead to a substantial displacement of the retrieved $\mathrm{CTH}$; in particular, when a local temperature minimum below a temperature inversion is missed by the bottom-up retrieval. Possible reasons for uncertainties in the temperature profile are the vertical resolution of the NWP model the profile is taken from, smoothing by the horizontal interpolation from the model grid to the place of observation and/or a temporal mismatch between simulated temperature profile and observation (Menzel et al., 2008). Additionally, the assimilation and forecast process of the NWP model have some uncertainties, in particular in the boundary layer.

In Fig. 13 the boundary layer clouds are located at $1.3 \mathrm{~km}$ according to CALIOP. This corresponds to the top of the boundary layer and is the central height of the temperature inversion. The temperature profile in Fig. 13 fails to reproduce the observed temperature minimum of $281 \mathrm{~K}$ by almost $2 \mathrm{~K}$. A possible explanation that the observed relative temperature minimum of $281 \mathrm{~K}$ is not reached at this height could be an underestimation of the boundary layer thickness by about $500 \mathrm{~m}$, assuming the same lapse rate as in the lower boundary layer.

The SEVIRI retrievals of this study derive the CTH of low clouds with following methods: The EUM algorithm uses a bottom-up approach to derive the CTH. According to the assumed ECMWF temperature profile, EUM misses the correct cloud location at the temperature inversion. The observed CTT of $281 \mathrm{~K}$ translates into a CTH of $2.9 \mathrm{~km}$ as it is retrieved by the EUM algorithm, see Fig. 13. Compared to CALIOP, EUM overestimates the CTH by about $1.6 \mathrm{~km}$ for this particular segment. The approach of the MPF algorithm is similar to EUM, but MPF uses an inversion correction (Lutz et al., 2011). If an inversion is detected, CTP and CTT are readjusted to the properties of the inversion. Therefore, the reported CTT of $284 \mathrm{~K}$ is also different from other SEVIRI retrievals.

CMS also corrects the CTH when an inversion is detected. If the temperature profile contains an inversion and the observed CTT is close enough to the temperature minimum of this inversion $(5 \mathrm{~K}$ in case of a non subsident and $10 \mathrm{~K}$ in case of a subsident thermal inversion), the CTH is adjusted to the height of the inversion. A thermal inversion is called subsident if the relative humidity between 850 and $600 \mathrm{hPa}$ is lower than $30 \%$. The exact location of the replaced CTH depends on the inversion properties. In contrast to MPF, the CMS algorithm does not modify the CTT accordingly ${ }^{1}$.

\footnotetext{
${ }^{1}$ The version of the MFR algorithm in 2014 uses the same CTH correction for temperature inversions. But the MFR data set used in
}

Instead of using data from NWP models, the temperature profile in the lower atmosphere can also be extrapolated from the surface temperature assuming a constant lapse rate (Minnis and Harrison, 1984; Minnis et al., 1992). Many strategies for calculation of the lapse rate have been suggested: Holz et al. (2008) found an overestimation of about $1 \mathrm{~km}$ for marine low-level stratus clouds for MODIS collection 5 when matching the observed radiance to temperature and water vapor profiles from the Global Data Assimilation System (GDAS). They noted that the overestimation is reduced remarkably when using a constant lapse rate and the GDAS ocean surface temperature. Dong et al. (2008) compared CERES-MODIS with lidar measurements from the ARM site. They selected cloud situations such that only fully covered, single layer stratus clouds were examined and it was found that the effective CTH was $0.534 \mathrm{~km}$ lower than the cloud tops retrieved from lidar-radar measurements when using a constant lapse rate. In contrast when using temperature profiles from the Goddard Earth Observing System (GEOS) model or soundings from the ARM site, the bias of the CTH retrieval reversed its sign and MODIS overestimated the physical CTH by 0.669 and $0.396 \mathrm{~km}$, respectively. Wu et al. (2008) suggested to calculate a local climatological lapse rate by using collocated measurements of AMSR-E, CALIOP and MODIS. A zonally dependent lapse rate was derived with this approach. The implementation and benefits of this method for the MODIS collection 5 and 6 data sets are described in Menzel et al. (2008) and Baum et al. (2012).

GSF and LAR make use of the lapse rate method for the retrieval of the CTH of low clouds. The GSF algorithm retrieves the CTH by optimal estimation. But for low clouds $(\mathrm{CTP}>600 \mathrm{hPa})$, this result is replaced with a result of a radiance fitting algorithm. Over land, the $10.8 \mu \mathrm{m}$ brightness temperature is matched to a NWP temperature profile. Over the ocean the $10.8 \mu \mathrm{m}$ brightness temperature is matched with the temperature profile constructed with a constant lapse rate. For the case investigated in Fig. 13 in August 2013 at $25^{\circ} \mathrm{S}$ over ocean, GSF assumes a temperature gradient of $5.4 \mathrm{~K} \mathrm{~km}^{-1}$. The constructed temperature profile is illustrated in Fig. 13. The approach of LAR is similar and described in detail by Minnis et al. (2010).

In future the approach of a zonally dependent lapse rate used for the LAR and GSF algorithms will be refined even further. Sun-Mack et al. (2014) demonstrated that this method on average results in a CTH overestimation over the marine stratus areas. Regionally and seasonally dependent lapse rates remove the longitudinal biases introduced by the zonal mean lapse rates and significantly reduce the CTH uncertainties for low clouds. Spatially resolved lapse rate climatologies are being used in the CERES Edition 4 analyses of MODIS data and will be used in future LAR analyses.

this study was submitted in 2006 when the MFR algorithm did not yet have this feature. 
In summary, the choice for one specific method to convert CTT to CTH in the boundary layer depends on the accuracy of the NWP temperature profile and details of the construction of temperature lapse rate. Different approaches must be individually calibrated to provide optimal results for $\mathrm{CTH}$ retrievals. Therefore, this issue will remain subject of future investigations.

Apart from the temperature profile, some other issues complicate the retrieval of the CTH for low clouds. The observed brightness temperature is influenced by the water vapor profile. For both water vapor and temperature, the simulation uncertainties of NWP models are generally greatest near the surface. Furthermore, boundary layer clouds are often broken. Hence, the measured signal is also influenced by the cloud fraction and the surface. Another challenge is that in cases of strong inversions, the droplets in the cloud top may actually be colder than the ambient air as a result of evaporation and radiative cooling (Painemal et al., 2013). This would preclude a match of a temperature profile of an NWP model or radiosonde with the observed CTT at the correct $\mathrm{CTH}$. Moreover, the difference between the surface and cloud top temperatures is small and therefore also the difference between clear and cloudy sky thermal radiances. Undetected aerosols and thin cirrus clouds above the boundary layer clouds may influence this small clear-cloudy radiance difference. In these cases the observed brightness temperature decreases; and hence, the derived CTH is distorted upwards. Finally, in cold regions (otherwise negligible) the instrument noise is noticeable and hampers the $\mathrm{CTH}$ retrieval.

\section{Conclusions}

In this paper ten SEVIRI cloud top height data sets from different research institutes in Europe and the USA are compared and validated. For this purpose, a retrieval database of five golden days was installed within the framework of the Cloud Retrieval Evaluation Workshop (CREW). It is the first time since the pre-ISCCP algorithm inter-comparisons (Rossow et al., 1985) that such a large number of Level 2 algorithms are evaluated with exactly the same methodology.

In the first part of the paper, we describe the retrieval methods and compare the SEVIRI CTH retrievals with each other. All retrievals capture the latitudinal distribution of the CTP similarly. The retrievals deviate from each other by less than $20 \%$ in the extratropics and by less than $40 \%$ in the tropics. We observe that the largest differences of the retrieved cloud top pressure values occur for broken clouds, thin cirrus layers and multi-layer clouds, in particular in the vicinity of tropical deep convection. The best agreement between the SEVIRI algorithms is found for marine stratocumulus that are closest to fulfilling the common retrieval assumption of horizontal homogeneity. In addition, the algorithms agree well for the centers of deep convective systems, where clouds are optically thick. Most algorithms retrieve a vertical frequency distribution of cloud top heights with two maxima: the first maximum is located between 700 and $900 \mathrm{hPa}$ (between 1 and $3 \mathrm{~km}$ ) representing boundary layer clouds and a second maximum between 200 and $300 \mathrm{hPa}$ (between 9 and $12 \mathrm{~km}$ ) corresponding to high cirrus and deep convective clouds.

In the second part of the paper, we compare the SEVIRI retrievals with observations from CALIOP and CPR along the path of the A-train satellite constellation. The cloud data sets are reduced to cases for which all data sets provide a retrieved CTP, the so called common mask, to exclude the effect of the individual cloud detection methods and to focus on the differences among the CTH retrievals. As result, many CALIOP observations of optically thin clouds are excluded in this way from the analysis. As CPR suffers from ground clutter and deviation of the SEVIRI cloud detection for broken cloud fields, some boundary layer clouds are also excluded.

For the CALIOP and CPR data sets with their individual cloud masks, the vertical cloud occurrence distributions show relative maxima at the heights of the tropical tropopause layer, the extratropical tropopause, the melting layer $(6.5 \mathrm{~km})$ and the boundary layer. After reducing the data sets to the common mask, these maxima are less pronounced. For most SEVIRI retrievals, only the maxima at the boundary layer and the tropopause can be identified. The correlations of the SEVIRI data sets with CALIOP and CPR measurements are between 0.77 and 0.90 . The mean SEVIRI CTHs are 1.1 to $2.5 \mathrm{~km}$ lower than the CALIOP measurement, as CALIOP is more sensitive to optically thin clouds. The differences between the SEVIRI CTHs and CPR range from -0.8 to $0.6 \mathrm{~km}$.

Following this, we repeat the same validation, but this time the cloud structures are separated into three regimes: optically thin and thick single layer clouds and multi-layer clouds. For optically thick single layer clouds the correlation coefficients between the SEVIRI and the reference data sets are generally above 0.95 and the biases are on the order of a few hundred meters.

The retrieval uncertainty for optically thin clouds is greater than for optically thick clouds. The correlation coefficients between the SEVIRI and the reference data sets are larger than 0.92. The mean SEVIRI CTHs are 0.2 to $1.1 \mathrm{~km}$ lower than CALIOP measurements. In comparison to CPR, the mean CTHs are similar for most algorithms, but two groups underestimate the CTH by more than $600 \mathrm{~m}$.

The CTH retrieval is very challenging for multi-layer clouds. The SEVIRI algorithms yield mean CTHs that are 2.1 to $4.4 \mathrm{~km}$ lower than the uppermost CALIOP CTHs and the correlation coefficients are between 0.59 and 0.83 . In comparison to CPR, most SEVIRI algorithms retrieve similar mean CTHs, but for three algorithms the mean CTH is about $1 \mathrm{~km}$ lower than and for one algorithm about $1 \mathrm{~km}$ higher than the CPR measurement. The correlation coefficients are between 0.64 and 0.78 . 
Additionally, a detailed analysis of the dependencies of the bias and root mean square difference (rmsd) of the SEVIRI algorithms on the CALIOP cloud optical depth $\tau_{\text {cal }}$ for single and multi-layer clouds is examined. The bias and rmsd are greater for small $\tau_{\text {cal. }}$. For single layer clouds bias and rmsd are roughly half as large as for all cloud cases.

A promising way to improve $\mathrm{CTH}$ retrievals for multilayer situations is to extend the cloud retrieval methods commonly assuming a single layer cloud situation so that they are able to derive cloud properties for a second underlying cloud layer, as done by Watts et al. (2011). The use of more SEVIRI satellite channels, especially the water vapor channels 6.2 and $7.3 \mu \mathrm{m}$, is required for this approach.

Finally, we investigate the accuracy of the SEVIRI retrievals for low clouds. We perform a small case study for a horizontally homogeneous marine stratocumulus region. Most of the algorithms slightly overestimate the CTH compared to CALIOP. The CTH deviations are primarily caused by uncertainties in and limited vertical resolution of the assumed atmospheric temperature profile. In the case of temperature inversions, the CTH retrieval solution may be ambiguous. The correct solution can even be missed, if the temperature profile does not represent the temperature inversion accurately enough. Therefore, some groups use alternative approaches trying to avoid these issues. If an inversion is detected, the MPF algorithm changes the CTH to the height of the inversion. The algorithm also adjust the CTT accordingly, hence, the CTT is different to the other algorithms. The CMS algorithm uses the height of the temperature inversion as CTH as well, if the CTT is slightly lower than the minimum temperature at the inversion. But CMS does not adjust the CTT according to the temperature profile. The GSF and LAR algorithms use fixed or climatological lapse rates for marine stratocumulus regions instead of the data from NWP models for clouds below $600 \mathrm{hPa}$ over the ocean. In this way, no ambiguities occur. Even though the problems of retrieving the CTH of boundary layer clouds are known, this issue will remain the subject of future research.

This is the first paper presenting a validation using the CREW database. As many more cloud parameters are included in this database, various future studies are possible. A comparison of cloud detection abilities would be very useful to work towards a common definition of a cloud mask, especially for broken and optically thin clouds. A comparison of the cloud phase, cloud optical depth and cloud effective radius would help to understand retrieval uncertainties and facilitate the use of retrieval data sets for the validation of weather and climate models. The CREW project plans to extend the validation to other satellite sensors, other domains and time periods. The CREW database already contains AVHRR, MODIS and POLDER, while some groups intend to analyze common data sets from VIIRS. The DARDAR data set (Delanoë and Hogan, 2008, 2010) would be another useful data set for the validation of passive imager retrievals. Finally, multi-retrieval validation of NWP model data are foreseeable, where the comparability of the model data could be achieved, for example, by simulating synthetic satellite observation using the CFMIP Observation Simulator Package (COSP, Bodas-Salcedo et al., 2011).

Our project website www.icare.univ-lille1.fr/crew provides further information about intentions and goals of the CREW project, the CREW database and participating institutes as well as the inter-comparison and validation methods. It also gives an overview of the four CREW meetings in 2006, 2009, 2011 and 2014, including the workshop program and the participant lists, provides contact information of the scientific board of CREW and gives access to reports and documents. All institutions with an advanced retrieval for cloud physical properties are invited to join the CREW validation activities.

Acknowledgements. This work was done in the framework of a EUMETSAT fellowship named CLOUDSTATE. We like to thank EUMETSAT for the funding of this fellowship and the Cloud Retrieval Evaluation Workshops. We thank the ICARE Data and Services Center (http://www.icare-lille1.fr) for providing computing support and access to the data used in these studies and for general support to the CREW project. We thank Frank Fell and EUMETSAT for providing the AVAC-S software that was used extensively for this research. The views, opinions, and findings contained in this report are those of the author(s) and should not be construed as an official National Oceanic and Atmospheric Administration or US Government position, policy or decision.

Edited by: A. Kokhanovsky

\section{References}

Avery, M., Winker, D., Heymsfield, A., Vaughan, M., Young, S., $\mathrm{Hu}$, Y., and Trepte, C.: Cloud ice water content retrieved from the CALIOP space-based lidar, Geophys. Res. Lett., 39, L05808, doi:10.1029/2011GL050545, 2012.

Baum, B. A. and Wielicki, B. A.: Cirrus cloud retrieval using infrared sounding data: Multilevel cloud errors, J. Appl. Meteorol., 33, 107-117, 1994.

Baum, B., Heymsfield, A., Yang, P., and Bedka, S.: Bulk scattering models for the remote sensing of ice clouds. Part 1: Microphysical data and models, J. Appl. Meteorol., 44, 1885-1895, 2005.

Baum, B., Yang, P., Heymsfield, A., Platnick, S., King, M., Hu, Y.X., and Bedka, S.: Bulk scattering models for the remote sensing of ice clouds. Part 2: Narrowband models, J. Appl. Meteorol., 44, 1896-1911, 2005.

Baum, B., Yang, P., Nasiri, S., Heidinger, A., Heymsfield, A., and Li, J.: Bulk scattering properties for the remote sensing of ice clouds. Part 3: High resolution spectral models from 100 to $3250 \mathrm{~cm}-1$, J. Appl. Meteorol., 46, 423-434, 2007.

Baum, B. A., Menzel, W. P., Frey, R. A., Tobin, D. C., Holz, R. E., Ackerman, S. A., Heidinger, A. K., and Yang, P.: MODIS cloudtop property refinements for Collection 6, J. Appl. Meteorol. Clim., 51, 1145-1163, 2012. 
Banks, J. R. and Brindley, H. E.: Evaluation of MSG-SEVIRI mineral dust retrieval products over North Africa and the Middle East, Remote Sens. Env., 128, 58-73, 2013.

Bennartz, R., Fell, F., and Walther, A.: AVAC-S: A-Train Validation of Aerosol and Cloud properties from SEVIRI, EUMETSAT document, 2010.

Bodas-Salcedo, A., Webb, M., Bony, S., Chepfer, H., Dufresne, J.L., Klein, S., Zhang, Y., Marchand, R., Haynes, J., Pincus, R., and John, V. O.: COSP: satellite simulation software for model assessment, B. Am. Meteorol. Soc., 92, 1023-1043, 2011.

Boucher, O.: Air traffic may increase cirrus cloudiness, Nature, 397, 30-31, 1999.

Breon, F.-M., Vermeulen, A., and Descloitres, J.: An evaluation of satellite aerosol products against sunphotometer measurements, Remote Sens. Environ., 115, 12, 3102-3111, 2011.

Brindley, H. E. and Russell, J. E.: Improving GERB scene identification using SEVIRI: infrared dust detection strategy, Remote Sens. Env., 104, 426-446, 2006.

Brindley, H., Knippertz, P., Ryder, C., and Ashpole, I.: A critical evaluation of the ability of the Spinning Enhanced Visible and Infrared Imager (SEVIRI) thermal infrared red-green-blue rendering to identify dust events: Theoretical analysis, J. Geophys. Res., 117, D07201, doi:10.1029/2011JD017326, 2012.

Bugliaro, L., Zinner, T., Keil, C., Mayer, B., Hollmann, R., Reuter, M., and Thomas, W.: Validation of cloud property retrievals with simulated satellite radiances: a case study for SEVIRI, Atmos. Chem. Phys., 11, 5603-5624, doi:10.5194/acp-115603-2011, 2011.

Cavia, F. and Tomassini, C.: Détermination de la température des cirrus semi-transparents, La Météorologie, 6, 63-67, 1978.

Cess, R. D., Potter, G., Blanchet, J., Boer, G., Ghan, S., Kiehl, J., Le Treut, H., Li, Z.-X., Liang, X.-Z., Mitchell, J., Morcrette, J.J., Randall, D. A., Riches, M. R., Roeckner, E., Schlese, U., Slingo, A., Taylor, K. E., Washington, W. M., Wetherald, R. T., and Yagai, I.: Interpretation of cloud-climate feedback as produced by 14 atmospheric general circulation models, Science, 245, 513-516, 1989.

Chahine, M. T.: Remote sounding of cloudy atmospheres, I. The single cloud layer, J. Atmos. Sci., 31, 233-243, 1974.

Chang, F.-L. and Li, Z.: A near-global climatology of single-layer and overlapped clouds and their optical properties retrieved from Terra/MODIS data using a new algorithm, J. Climate, 18, 47524771, 2005a.

Chang, F.-L. and Li, Z.: A new method for detection of cirrus overlapping water clouds and determination of their optical properties, J. Atmos. Sci., 62, 3993-4009, 2005b.

Chang, F.-L., Minnis, P., Lin, B., Khaiyer, M. M., Palikonda, R., and Spangenberg, D. A.: A modified method for inferring upper troposphere cloud top height using the GOES $12 \mathrm{im}$ ager 10.7 and $13.3 \mu \mathrm{m}$ data, J. Geophys. Res., 115, D06208, doi:10.1029/2009JD012304, 2010.

Cox, C. and Munk, W.: Measurement of the roughness of the sea surface from photographs of the sun's glitter, J. Optical Soc. Am., 44, 838-850, 1954.

Cox, C. and Munk, W.: Statistics of the sea surface derived from sun glitter, J. Marine Res., 13, 198-227, 1954.

Delanoë, J. and Hogan, R. J.: A variational scheme for retrieving ice cloud properties from combined radar, lidar, and infrared radiometer, J. Geophys. Res.-Atmos., 113, D07204, doi:10.1029/2007JD009000, 2008.

Delanoë, J. and Hogan, R. J.: Combined CloudSat-CALIPSOMODIS retrievals of the properties of ice clouds, J. Geophys. Res.-Atmos., 115, D00H29, doi:10.1029/2009JD012346, 2010.

De Pape, B. and Dewitte, S.: Dust aerosol optical depth retrieval over a desert surface using the SEVIRI window channels, J. Atmos. Oceanic. Technol., 26, 704-718, 2008.

Derrien, M. and Le Gléau, H.: MSG/SEVIRI cloud mask and type from SAFNWC, Int. J. Remote Sens., 26, 4707-4732, 2005.

Derrien, M. and Le Gléau, H.: Improvement of cloud detection near sunrise and sunset by temporal-differencing and regiongrowing techniques with real-time SEVIRI, Int. J. Remote Sens., 31, 1765-1780, 2010.

Derrien, M. and Le Gléau, H.: Algorithm Theoretical Basis Document for "Cloud Products" (CMa-PGE01 v3.2, CTPGE02 v2.2 \& CTTH-PGE03 v2.2), NWC SAF document: SAF/NWC/CDOP/MFL/SCI/ATBD/01, 2013.

Dong, X., Minnis, P., Xi, B., Sun-Mack, S., and Chen, Y.: Comparison of CERES-MODIS stratus cloud properties with ground-based measurements at the DOE ARM Southern Great Plains site, J. Geophys. Res.-Atmos., 113, D03204, doi:10.1029/2007JD008438, 2008.

Ewald, F., Bugliaro, L., Mannstein, H., and Mayer, B.: An improved cirrus detection algorithm MeCiDA2 for SEVIRI and its evaluation with MODIS, Atmos. Meas. Tech., 6, 309-322, doi:10.5194/amt-6-309-2013, 2013.

Eyre, J. R. and Menzel, W. P.: Retrieval of cloud parameters from satellite sounder data: A simulation study., J. Appl. Meteorol., 28, 267-275, 1989.

Francis, P. N., Hocking, J. A., and Saunders, R. W.: Improved diagnosis of low-level cloud from MSG SEVIRI data for assimilation into Met Office limited area models, Proceedings of the 2008 EUMETSAT Meteorological Satellite Conference, Darmstadt, 2008.

Govaerts, Y., Arriaga, A., and Schmetz, J.: Operational vicarious calibration of the MSG/SEVIRI solar channels, Adv. Space Res., 28, 21-30, 2001.

Heidinger, A. K. and Pavolonis, M. J.: Gazing at cirrus clouds for 25 years through a split window, Part I: Methodology, J. Appl. Meteorol. Clim., 48, 1100-1116, 2009.

Heidinger, A., Pavolonis, M., Holz, R., Baum, B. A., and Berthier, S.: Using CALIPSO to explore the sensitivity to cirrus height in the infrared observations from NPOESS/VIIRS and GOES-R/ABI, J. Geophys. Res.-Atmos., 115, D00H20, doi:10.1029/2009JD012152, 2010.

Hewison, T. J. and Müller, J.: Ice Contamination of Meteosat/SEVIRI Implied by Intercalibration Against Metop/IASI, IEEE Trans. Geosci. Remote Sens., 51, 3, 1182-1186, doi:10.1109/TGRS.2012.2236335, 2013.

Holz, R. E., Ackerman, S., Antonelli, P., Nagle, F., Knuteson, R. O., McGill, M., Hlavka, D. L., and Hart, W. D.: An improvement to the high-spectral-resolution $\mathrm{CO}_{2}$-slicing cloud-top altitude retrieval, J. Atmos. Ocean Tech., 23, 653-670, 2006.

Holz, R., Ackerman, S., Nagle, F., Frey, R., Dutcher, S., Kuehn, R., Vaughan, M., and Baum, B.: Global Moderate Resolution Imaging Spectroradiometer (MODIS) cloud detection and height evaluation using CALIOP, J. Geophys. Res.-Atmos., 113, D00A19, doi:10.1029/2008JD009837, 2008. 
Hostetler, C., Liu, Z., Reagan, J., Vaughan, M., Winker, D., Osborn, M., Hunt, W., Powell, K., and Trepte, C.: CALIOP Algorithm Theoretical Basis Document - Part 1: Calibration and Level 1 Data Products, Doc. PC-SCI, 201, 2006.

$\mathrm{Hu}, \mathrm{Y}$. X. and Stamnes, K.: An accurate parameterization of the radiative properties of water clouds suitable for use in climate models, J. Climate, 6, 728-742, 1993.

Hurley, J., Dudhia, A., and Grainger, R. G.: Retrieval of macrophysical cloud parameters from MIPAS: algorithm description, Atmos. Meas. Tech., 4, 683-704, doi:10.5194/amt-4-683-2011, 2011.

Joiner, J., Vasilkov, A. P., Bhartia, P. K., Wind, G., Platnick, S., and Menzel, W. P.: Detection of multi-layer and vertically-extended clouds using A-train sensors, Atmos. Meas. Tech., 3, 233-247, doi:10.5194/amt-3-233-2010, 2010.

Karlsson, K-G., and E. Johansson: On the optimal method for evaluating cloud products from passive satellite imagery using CALIPSO-CALIOP data: example investigating the CM SAF CLARA-A1 dataset, Atmos. Meas. Tech., 6, 1271-1286, doi:10.5194/amt-6-1271-2013, 2013.

King, M. D., Platnick, S., Hubanks, P. A., Arnold, G. T., Moody, E. G., Wind, G., and Wind, B.: Collection 005 change summary for the MODIS cloud optical property (06_OD) algorithm, MODIS Atmosphere, 8 pp., 2006.

Li, J., Zhang, P., Schmit, T. J., Schmetz, J., and Menzel, W. P.: Quantitative monitoring of a Saharan dust event with SEVIRI on Meteosat-8, Int. J. Remote Sens., 28, 2181-2186, 2007.

Lindstrot, R., Preusker, R., and Fischer, J.: Remote sensing of multilayer cloud-top pressure using combined measurements of MERIS and AATSR on board Envisat, J. Appl. Meteorol. Clim., 49, 1191-1204, 2010.

Liou, K.-N.: Influence of cirrus clouds on weather and climate processes: a global perspective, Mon. Weather Rev., 114, 11671199, 1986.

Liou, K.-N.: An Introduction to Atmospheric Radiation, vol. 84, access online via Elsevier, 2002.

Liu, Z., Omar, A., Hu, Y., Vaughan, M., Winker, D., Poole, L., and Kovacs, T.: CALIOP algorithm theoretical basis document, Part 3: Scene classification algorithms, NASA-CNES document PCSCI-203, 2005.

Lutz, H.-J., Wilson, H. K., Heinemann, T., Samain, O., Gustafsson, J., Holmlund, K., and de Smet, A.: MSG Meteorological Products Extraction Facility Algorithm Specification Document, EUMETSAT Document Nr. EUM/MSG/SPE/022, 2011.

Masuda, K., Takashima, T., and Takayama, Y.: Emissivity of pure and sea waters for the model sea surface in the infrared window regions, Remote Sens. Environ., 24, 313-329, 1988.

Meerkötter, R. and Bugliaro, L.: Diurnal evolution of cloud base heights in convective cloud fields from MSG/SEVIRI data, Atmos. Chem. Phys., 9, 1767-1778, doi:10.5194/acp-9-1767-2009, 2009.

Meirink, J. F., Roebeling, R. A., and Stammes, P.: Inter-calibration of polar imager solar channels using SEVIRI, Atmos. Meas. Tech., 6, 2495-2508, doi:10.5194/amt-6-2495-2013, 2013.

Menzel, W., Smith, W., and Stewart, T.: Improved cloud motion wind vector and altitude assignment using VAS, J. Clim. Appl. Meteorol., 22, 377-384, 1983.

Menzel, W. P., Frey, R. A., Zhang, H., Wylie, D. P., Moeller, C. C., Holz, R. E., Maddux, B., Baum, B. A., Strabala, K. I., and Gum- ley, L. E.: MODIS global cloud-top pressure and amount estimation: algorithm description and results, J. Appl. Meteorol. Clim., 47, 1175-1198, 2008.

Meyer, R., Mannstein, H., Meerkötter, R., Schumann, U., and Wendling, P.: Regional radiative forcing by line-shaped contrails derived from satellite data, J. Geophys. Res., 107, ACL-1-ACL17, doi:10.1029/2001JD00426, 2002.

Minnis, P. and Harrison, E. F.: Diurnal variability of regional cloud and clear-sky radiative parameters derived from GOES data, Part II: November 1978 cloud distributions, J. Clim. Appl. Meteorol., 23, 1012-1031, 1984.

Minnis, P., Heck, P. W., Young, D. F., Fairall, C., and Snider, J.: Stratocumulus cloud properties derived from simultaneous satellite and island-based instrumentation during FIRE, J. Appl. Meteorol., 31, 317-339, 1992.

Minnis, P., Nguyen, L., Doelling, D. R., Young, D. F., Miller, W. F., and Kratz, D. P.: Rapid calibration of operational and research meteorological satellite imagers, Part I: Evaluation of research satellite visible channels as references, J. Atmos. Oceanic Technol., 19, 1233-1249, 2002.

Minnis, P., Nguyen, L., Doelling, D. R., Young, D. F., Miller, W. F., and Kratz, D. P.: Rapid calibration of operational and research meteorological satellite imagers, Part II: Comparison of infrared channels, J. Atmos. Oceanic Technol., 19, 1250-1266, 2002.

Minnis, P., Huang, J., Lin, B., Yi, Y., Arduini, R. F., Fan, T.-F., Ayers, J. K., and Mace, G. G.: Ice cloud properties in ice-overwater cloud systems using Tropical Rainfall Measuring Mission (TRMM) visible and infrared scanner and TRMM Microwave Imager data, J. Geophys. Res.-Atmos., 112, D06206, doi:10.1029/2006JD007626, 2007.

Minnis, P., Trepte, Q. Z., Sun-Mack, S., Chen, Y., Doelling, D. R., Young, D. F., Spangenberg, D. A., Miller, W. F., Wielicki, B. A., Brown, R. R., Gibson, S. C., and Geier, E. B.: Cloud detection in nonpolar regions for CERES using TRMM VIRS and Terra and Aqua MODIS data, IEEE T. Geosci. Remote, 46, 3857-3884, 2008a.

Minnis, P., Yost, C. R., Sun-Mack, S., and Chen, Y.: Estimating the top altitude of optically thick ice clouds from thermal infrared satellite observations using CALIPSO data, Geophys. Res. Lett., 35, L12801, doi:10.1029/2008GL033947, 2008b.

Minnis, P., Sun-Mack, S., Trepte, Q. Z., Chang, F.-L., Heck, P. W., Chen, Y., Yi, Y., Arduini, R. F., Ayers, K., Bedka, K., Bedka, S., Brown, R., Gibson, S., Heckert, E., Hong, G., Jin, Z., Palikonda, R., Smith, R., Smith, W. L. J., Spangenberg, D. A., Yang, P., Yost, C. R., and Xie, Y.: CERES Edition 3 Cloud Retrievals, AMS 13th Conf. Atmos. Rad. 2010, Portland, 2010.

Minnis, P., Sun-Mack, S., Young, D. F., Heck, P. W., Garber, D. P., Chen, Y., Spangenberg, D. A., Arduini, R. F., Trepte, Q. Z., Smith, W. L., Ayers, J. K., Gibson, S. C., Miller, W. F., Chakrapani, V., Takano, Y., Liou, K.-N., Xie, Y., and Yang, P.: CERES edition-2 cloud property retrievals using TRMM VIRS and Terra and Aqua MODIS data, Part I: Algorithms, IEEE T. Geosci. Remote, 49, 4374-4400, 2011.

Moseley, S.: Changes to the Nimrod cloud top height diagnosis, Met Office Forecasting Research Technical Report, 424, 2003.

Painemal, D., Minnis, P., and O'Neill, L.: The diurnal cycle of boundary layer height and cloud cover over the Southeast Pacific as observed by GOES-10, J. Atmos. Sci., 70, 2393-2408, 2013. 
Parajuli, S. P., Gherboudj, I., and Ghedira, H: The effect of soil moisture and wind speed on aerosol optical thickness retrieval in a desert environment using SEVIRI thermal channels, Int. J. Remote Sens., 34, 14, 5054-5071, 2013.

Pavolonis, M. J. and Heidinger, A. K.: Daytime cloud overlap detection from AVHRR and VIIRS, J. Appl. Meteorol., 43, 762-778, 2004.

Platnick, S., King, M. D., Ackerman, S. A., Menzel, W. P., Baum, B. A., Riédi, J. C., and Frey, R. A.: The MODIS cloud products: algorithms and examples from Terra, IEEE T. Geosci. Remote, 41, 459-473, 2003.

Poulsen, C. A., Siddans, R., Thomas, G. E., Sayer, A. M., Grainger, R. G., Campmany, E., Dean, S. M., Arnold, C., and Watts, P. D.: Cloud retrievals from satellite data using optimal estimation: evaluation and application to ATSR, Atmos. Meas. Tech., 5, 1889-1910, doi:10.5194/amt-5-1889-2012, 2012.

Ray, P. S.: Broadband complex refractive indices of ice and water, Applied Optics, 11, 8, 1836-1844; doi:10.1364/AO.11.001836, 1972.

Rodgers, C. D.: Inverse Methods for Atmospheric Sounding: Theory and Practice, Series on Atmospheric, Ocean. Planet. Phys., 2, World Scentic, Singapore, 238 pp., 2000.

Roebeling, R.: Cloud Physical Properties Retrieval for Climate Studies using SEVIRI and AVHRR data, Ph.D. thesis, Wageningen University, the Netherlands, 2008.

Roebeling, R., Feijt, A., and Stammes, P.: Cloud property retrievals for climate monitoring: implications of differences between Spinning Enhanced Visible and Infrared Imager (SEVIRI) on METEOSAT-8 and Advanced Very High Resolution Radiometer (AVHRR) on NOAA-17, J. Geophys. Res.-Atmos., 111, D20210, doi:10.1029/2005JD006990, 2006.

Roebeling, R., Baum, B., Bennartz, R., Hamann, U., Heidinger, A., Thoss, A., and Walther, A.: Evaluating and improving cloud parameter retrievals, B. Am. Meteorol. Soc., 94, ES41-ES44, 2012.

Romano, F., Ricciardelli, E., Cimini, D., Di Paola, F., and Viggiano, M.: Dust Detection and Optical Depth Retrieval Using MSG SEVIRI Data, Atmosphere, 4, 35-47, doi:10.3390/atmos4010035, 2013.

Rossow, W. B. and Schiffer, R. A.: Advances in understanding clouds from ISCCP, B. Am. Meteorol. Soc., 80, 2261-2287, 1999.

Rossow, W., Mosher, F., Kinsella, E., Arking, A., Desbois, M., Harrison, E., Minnis, P., Ruprecht, E., Seze, G., Simmer, C., and Smith, E.: ISCCP cloud algorithm intercomparison, J. Clim. Appl. Meteorol., 24, 877-903, 1985.

Salisbury, J. W. and D'Aria, D. M.: Emissivity of terrestrial materials in the $8-14 \mu \mathrm{m}$ atmospheric window, Remote Sens. Environ., 42, 83-106, 1992.

Sannazzaroa, F., Filizzolab, C., Marcheseb, F., Corradoa, R., Paciellob, R., Mazzeob, G., Pergolab, N., and Tramutolia, V.: Identification of dust outbreaks on infrared MSG-SEVIRI data by using a Robust Satellite Technique (RST), Acta Astronautica, 93, 6470, 2014.

Saunders, R., Francis, R., Francis, P., Crawford, J., Smith, A., Brown, I., Taylor, R., Forsythe, M., Doutriaux-Boucher, M., and Millington, S.: The exploitation of Meteosat Second Generation Data in the Met Office, Proceedings of the 2006 EUMETSAT Meteorological Satellite Conference, Helsinki, 2006.
Schepanski, K., Tegen, I., and Macke, A.: Comparison of satellite based observations of Saharan dust source areas, Remote Sens. Environ., 123, 90-97, 2012.

Schmetz, J., Holmlund, K., Hoffman, J., Strauss, B., Mason, B., Gaertner, V., Koch, A., and Van De Berg, L.: Operational cloudmotion winds from Meteosat infrared images, J. Appl. Meteorol., 32, 1206-1225, 1993.

Schmetz, J., Pili, P., Tjemkes, S., Just, D., Kerkmann, J., Rota, S., and Ratier, A.: An introduction to Meteosat second generation (MSG), B. Am. Meteorol. Soc., 83, 977-992, 2002.

Schumann, U., Mayer, B., Graf, K., and Mannstein, H.: A parametric radiative forcing model for contrail cirrus, J. Appl. Meteorol. Clim., 51, 1391-1406, 2012.

Seemann, S. W., Borbas, E. E., Knuteson, R. O., Stephenson, G. R., and Huang, H.-L.: Development of a global infrared land surface emissivity database for application to clear sky sounding retrievals from multispectral satellite radiance measurements, J. Appl. Meteorol. Clim., 47, 108-123, 2008.

Sherwood, S. C., Chae, J.-H., Minnis, P., and McGill, M.: Underestimation of deep convective cloud tops by thermal imagery, Geophys. Res. Lett., 31, L11102, doi:10.1029/2004GL019699, 2004.

Shettle, E.: Models of aerosols, clouds and precipitation for atmospheric propagation studies, Atmospheric propagation in the UV, visible, IR and mm-region and related system aspects, no. 454 in AGARD Conference Proceedings, 1989.

Smith, W. L. and Frey, R.: On cloud altitude determinations from high resolution interferometer sounder (HIS) observations, J. Appl. Meteorol., 29, 658-664, 1990.

Smith, W. and Platt, C.: Comparison of satellite-deduced cloud heights with indications from radiosonde and ground-based laser measurements, J. Appl. Meteorol., 17, 1796-1802, 1978.

Smith, W. L. and Frey, R.: On cloud altitude determinations from high resolution interferometer sounder (HIS) observations, J. Appl. Meteorol., 29, 658-662, 1990.

Stephens, G. L., Vane, D. G., Boain, R. J., Mace, G. G., Sassen, K., Wang, Z., Illingworth, A. J., O'Connor, E. J., Rossow, W. B., Durden, S. L., Miller, S. D., Austin, R. T., Benedetti, A., Mitrescu, C., and The CloudSat Science Team: The CloudSat mission and the A-Train: a new dimension of space-based observations of clouds and precipitation, B. Am. Meteorol. Soc., 83, 1771-1790, 2002.

Stephens, G. L., Vane, D. G., Tanelli, S., Im, E., Durden, S., Rokey, M., Reinke, D., Partain, P., Mace, G. G., Austin, R., L'Ecuyer, T., Haynes, J., Lebsock, M., Suzuki, K., Waliser, D., Wu, D., Kay, J., Gettelman, A., Wang, Z., and Marchand, R.: CloudSat mission: performance and early science after the first year of operation, J. Geophys. Res., 113, D00A18, doi:10.1029/2008JD009982, 2008.

Stubenrauch, C., Rossow, W., Kinne, S., Ackerman, S., Cesana, G., Chepfer, H., Di Girolamo, L., Getzewich, B., Guignard, A., Heidinger, A. Maddux, B. C., Menzel, W. P., Minnis, P., Pearl, C., Platnick, S., Poulsen, C., Riedi, J., Sun-Mack, S., Walther, A., Winker, D., Zeng, S., and Zhao, G.: Assessment of global cloud datasets from satellites: project and database initiated by the GEWEX Radiation Panel, B. Am. Meteorol. Soc., 94, 10311049, doi:10.1175/BAMS-D-12-00117, 2013.

Sun-Mack, S., Minnis, P., Chen, Y., Kato, S., Yi, Y., Gibson, S., Heck, P. W., and Winker, D.: Regional Apparent Boundary Layer 
Lapse Rates Determined from CALIPSO and MODIS Data for Cloud-Height Determination, J. Appl. Meteorol. Clim., 53, 4, 990-1011, 2014.

Tanelli, S., Durden, S. L., Im, E., Pak, K. S., Reinke, D. G., Partain, P., Haynes, J. M., and Marchand, R. T.: CloudSat's cloud profiling radar after two years in orbit: performance, calibration, and processing, IEEE T. Geosci. Remote, 46, 3560-3573, 2008.

Taylor, K. E.: Summarizing multiple aspects of model performance in a single diagram, J. Geophys. Res.-Atmos., 106, 7183-7192, 2001.

Vaughan, M., Winker, D. M., and Powell, K.: CALIOP algorithm theoretical basis document, Part 2: Feature detection and layer properties algorithms, Rep. PC-SCI-202, Release 1.01, 87 pp., 2005.

Walther, A. and Heidinger, A. K.: Implementation of the daytime cloud optical and microphysical properties algorithm (DCOMP) in PATMOS-x, J. Appl. Meteorol. Clim., 51, 1371-1390, 2012.

Watts, P., Bennartz, R., and Fell, F.: Retrieval of two-layer cloud properties from multispectral observations using optimal estimation, J. Geophys. Res.-Atmos., 116, , D16203, doi:10.1029/2011JD015883, 2011.

Wielicki, B. A. and Coakley Jr., J. A.: Cloud retrieval using infrared sounder data: error analysis, J. Appl. Meteorol., 20, 157-169, 1981.

Wielicki, B. A., Harrison, E. F., Cess, R. D., King, M. D., and Randall, D. A.: Mission to planet Earth: role of clouds and radiation in climate, B. Am. Meteorol. Soc., 76, 2125-2153, 1995.

Wind, G., Platnick, S., King, M. D., Hubanks, P. A., Pavolonis, M. J., Heidinger, A. K., Yang, P., and Baum, B. A.: Multilayer cloud detection with the MODIS near-infrared water vapor absorption band, J. Appl. Meteorol. Clim., 49, 2315-2333, 2010.
Winker, D. M., Pelon, J., and McCormick, M. P.: The CALIPSO mission: spaceborne lidar for observation of aerosols and clouds, in: Proc. Spie, vol. 4893, 11 pp., 2003.

Winker, D. M., Hunt, W. H., and McGill, M. J.: Initial performance assessment of CALIOP, Geophys. Res. Lett., 34, 19, L19803, doi:10.1029/2007GL030135, 2007.

Winker, D., Pelon, J., Coakley Jr, J., Ackerman, S., Charlson, R., Colarco, P., Flamant, P., Fu, Q., Hoff, R., Kittaka, C., Kubar, T. L., Le Treut, H., McCormick, M. P., Megie, G., Poole, L., Powell, K., Trepte, C., Vaughan, M. A., and Wielicki, B. A.: The CALIPSO mission: a global 3-D view of aerosols and clouds, Faculty Research Publications (College of Earth, Ocean, and Atmospheric Sciences), 2010.

Wu, D., Hu, Y., McCormick, M. P., Xu, K.-M., Liu, Z., Smith, B., Omar, A. H., and Chang, F.-L.: Deriving marine-boundary-layer lapse rate from collocated CALIPSO, MODIS, and AMSR-E data to study global low-cloud height statistics, IEEE Geosci. Remote Sens. Lett., 5, 649-652, 2008.

Wylie, D. P. and Menzel, W.: Two years of cloud cover statistics using VAS, J. Climate, 2, 380-392, 1989.

Zhang, H. and Menzel, W. P.: Improvement in thin cirrus retrievals using an emissivity-adjusted $\mathrm{CO}_{2}$ slicing algorithm, J. Geophys. Res.-Atmos., 107, 4327, doi:10.1029/2001JD001037, 2002.

Zinner, T. and Mayer, B.: Remote sensing of stratocumulus clouds: uncertainties and biases due to inhomogeneity, J. Geophys. Res. 111, D14209, doi:10.1029/2005JD006955, 2006. 